\title{
Transições entre situações de atividade, inatividade e estudo dos jovens nem-nem no Brasil - 2012/2016 *
}

\author{
Denise Guichard Freire ${ }^{\dagger}$ \\ João Saboia ${ }^{\ddagger}$
}

\begin{abstract}
Resumo
Os jovens que nem trabalham e nem estudam representam um conjunto expressivo no Brasil e têm recebido cada vez mais atenção na busca de seu melhor entendimento. Esse artigo apresenta uma resenha bibliográfica dos estudos já realizados sobre os jovens nem-nem brasileiros. Analisa pela primeira vez as probabilidades de permanência e de transição desses jovens entre as várias situações de atividade e frequência escolar a partir das informações da Pesquisa Nacional por Amostra de Domicílio Contínua (PNADC) no período 2012/2016, quando a economia passou por um processo de desaceleração e crise. Os resultados apontam para o dinamismo existente nas transições dentro do conjunto de jovens nem-nem
\end{abstract}

Palavras-chave: Nem-Nem, emprego de jovens, inatividade de jovens, escolaridade de jovens.

JEL: J00; J13

\section{Introdução}

O termo NEET "Not in Education, Employment, or Training"ou nem-nem (nem estuda e nem trabalha) não é recente, tendo surgido em meados dos anos 1980 no Reino Unido, apesar de ter sido mais divulgado e estudado após a crise econômica internacional de 2008-2009. É um conceito controverso, que não possui unanimidade, tendo em vista que abarca um conjunto heterogêneo de jovens com características e necessidades de políticas públicas e de ações distintas. Jovens que estão em situação de vulnerabilidade econômica e social agrupados com aqueles que não precisam de nenhuma ajuda.

Assim, a literatura internacional que trata da questão dos jovens nem-nem discute a heterogeneidade do conceito NEET e a necessidade de melhor filtrar esses jovens em

\footnotetext{
* Os autores agradecem a Antonio Etevaldo Teixeira pelo apoio na geração das informações e a dois pareceristas anônimos pelas críticas e sugestões feitas à primeira versão do artigo.

${ }^{\dagger}$ Doutora pelo Instituto de Economia da UFRJ e tecnologista do IBGE. E-mail: denisegfreire@gmail.com

${ }^{\ddagger}$ Professor Emérito do Instituto de Economia da UFRJ. E-mail: saboia1 @ globo.com.
} 
busca de conhecer os que realmente estejam em situação de vulnerabilidade. Propõe políticas públicas que podem ser tomadas para amenizar a situação dos jovens desempregados em decorrência da crise econômica internacional; discute a identificação do grupo de jovens que são nem-nem mesmo em países que não foram seriamente afetados pela crise econômica internacional de 2008/2009 e as consequências futuras para os jovens de estar nessa condição. E, ainda, analisa no longo prazo como a taxa nem-nem evolui em relação ao $\mathrm{PIB}^{1}$.

Observa-se, ainda, que não existe um padrão internacional que determine a faixa etária dos jovens. Alguns estudos internacionais consideram entre 15 e 24 anos, outros 15 a 29 anos ou ainda 15 a 34 anos. Nesse trabalho, é adotado o critério definido pela OCDE no relatório Education at a Glance, entre 15 e 29 anos, pois permitiria uma melhor comparação internacional na medida em que engloba países desenvolvidos e em desenvolvimento em suas estatísticas e permite melhor avaliar a condição do jovem brasileiro. Os estudos do Banco Mundial, por sua vez, abordam o tema para a faixa etária de 15 a 24 anos. Essa diferença etária impacta os resultados por gênero, por exemplo, pois na maioria dos casos existe uma inatividade feminina relevante na faixa de 25 a 29 anos $^{2}$.

A importância desse tema pode ser medida por sua dimensão. Em 2010, de acordo com o Banco Mundial, havia 260 milhões de jovens nem-nem no mundo, o que representava 2,2 jovens nem-nem a cada 10 jovens entre 15 e 24 anos de idade. Um fenômeno global que atinge as diferentes regiões mundiais de forma desigual. As taxas são mais elevadas nas regiões do Oriente Médio, Norte da África e Sudeste Asiático com 3 jovens nem-nem a cada 10 jovens. África Subsaariana, América Latina, Europa e Ásia Central apresentam indicadores medianos com cerca de 2 nem-nem a cada 10 jovens. As melhores condições para os jovens estão no Leste Asiático e Pacífico e nos países de renda alta com apenas 1,5 e 1 jovem nem-nem a cada 10, respectivamente.

Mesmo em países muito desenvolvidos existe uma parcela de jovens nem-nem, porém numa proporção muito baixa como na Alemanha ou na Islândia com 1 a cada 16 e 1 a cada 12 jovens, respectivamente. Seja por opção ou por necessidade, sempre há um grupo de jovens nesta condição. Entretanto, o caso brasileiro, de cerca de 1 em cada 4 ou 5, é uma situação desfavorável, em que pese estar dentro da média mundial. Existem países em outras regiões cujos jovens estão em situação ainda mais grave.

Portanto, os estudos com jovens nem-nem apontam que o problema ocorre mundialmente, com grande desigualdade entre as regiões mundiais e entre os países. A taxa é relativamente elevada, mesmo em alguns países desenvolvidos que foram afetados pela crise econômica de 2008/2009. Na Europa, a melhora da economia mundial a partir de 2013 tem reduzido paulatinamente a quantidade de jovens nesta condição no continente.

Nesse contexto, a América Latina está em uma situação intermediária, com muito a

\footnotetext{
${ }^{1}$ Ver, por exemplo, Serracant (2012), Dennett e Sasser Modestino (2013), Ose e Jansen (2017), O'Dea et al (2014), Egan, Daly e Delaney (2015).

${ }^{2}$ Ver De Hoyos, Rogers e Székely (2016) e De Hoyos, Popova e Rogers (2016).
} 
avançar na melhoria nas condições dos jovens. A taxa de jovens nem-nem era de 19,3\%, em 2010, o que representava 18 milhões de jovens. No Brasil, estavam um terço desses desses jovens, com uma taxa próxima à média da região.

Analisando a situação brasileira entre 1990 e 2010, de acordo com De Hoyos, Popova e Rogers (2016), os resultados apontam que a taxa média apresentou uma pequena redução. Contudo, a taxa média esconde uma importante mudança na sua composição por sexo. Houve uma redução da taxa feminina, enquanto a taxa masculina apresentou trajetória de crescimento. Com isso, a taxa feminina que era o triplo da masculina passou a ser o dobro, o que ainda representa uma situação crítica para as mulheres apesar dos avanços. Esta redução da taxa feminina relaciona-se à maior inserção das mulheres tanto no mercado de trabalho quanto no sistema educacional, que ocasionaram uma redução significativa da taxa de fecundidade e da necessidade das mulheres ficarem sem estudar e/ou trabalhar para cuidar da família ${ }^{3}$.

O aumento da participação masculina entre os nem-nem não ocorreu somente no Brasil, tendo ocorrido em outros países da América Latina, como o México (DE_HOYOS; FIERROS, C. G. e VARGAS, J. V.(2016) . Considerando o caso dos jovens europeus de 15 a 29 anos, a taxa de jovens nem-nem aumentou a partir de 2009 em decorrência da crise internacional e permaneceu elevada até 2013. Desde 2014, voltou a recuar, mas ainda permanece em um patamar superior ao do período pré-crise.

Observa-se uma baixa proporção de jovens brasileiros que estudam em comparação com os demais países. Entre esses jovens, uma parcela relativamente pequena conjuga estudo com trabalho. Por sua vez, a parcela dos jovens nem-nem era elevada na comparação com os demais países desenvolvidos e em desenvolvimento da OCDE, ficando abaixo somente dos países europeus fortemente atingidos pela crise econômica internacional.

Conforme será visto na próxima seção. os estudos realizados sobre os jovens nemnem brasileiros focam principalmente na parcela de jovens inativos. Os jovens nem-nem inativos são predominantemente mulheres, com baixo nível de escolaridade, provenientes de domicílios pobres, cônjuges, na maioria dos casos com filhos pequenos, de cor parda. As participações de mulheres sem filhos e de homens têm aumentado, inclusive entre aqueles com ensino médio completo.

Internacionalmente, os estudos focam não somente nos jovens inativos, mas também nos desocupados. Em que pese a importância dos jovens inativos no conjunto dos jovens brasileiros na condição nem-nem, seria relevante a sua compreensão dentro de um contexto mais amplo e afinado com o conceito internacionalmente aceito, inclusive para que se possa compreender a sua mobilidade entre inativos e desocupados. Ao se considerar

\footnotetext{
${ }^{3}$ As afirmações feitas na seção de introdução sobre a experiência brasileira estão baseadas na resenha feita na próxima seção onde estão mencionadas todas as referências encontradas de estudos sobre os nemnem no Brasil. Ver Camarano et al (2001), Camarano et al (2004), Camarano et al (2006), Leme e Wajnman (2000), Camarano e Kanso (2012), Cardoso (2013), Menezes-Filho et al (2013), Monteiro (2013), Cabanas et al (2014), Ciríaco (2015), Martins (2016) e Simões et al (2013).
}

Econômica-Niterói, v. 21, n. 1, p. 6-43. Junho, 2019 
que o jovem desocupado já fez uma opção pelo mercado de trabalho, apesar de não estar inserido nele, parte-se do pressuposto que sua situação seria menos grave que a dos inativos, o que não necessariamente ocorre. Em alguns casos, a inatividade é uma opção, enquanto a desocupação demonstra uma situação de vulnerabilidade econômica e social.

A presença de outro jovem inativo e de idosos na família tende a aumentar as chances de um jovem estar nesta condição. Em alguns casos, a condição nem-nem seria transitória, e o aumento da taxa observada recentemente seria decorrente do aumento do tempo de duração dos jovens menos escolarizados nesta condição, que teriam mais dificuldade de recolocação no mercado de trabalho. Em relação à renda, os jovens mais pobres apresentam um percentual de inatividade mais alto do que os demais.

Um ponto a salientar é que a maioria dos estudos, como será visto na próxima seção, aborda este tema do ponto de vista nacional. Não existem ainda estudos sobre as diferenças regionais dos jovens nem-nem considerando as profundas desigualdades econômicas do país.

As análises realizadas tendem a responsabilizar a falta de qualificação dos jovens pela sua dificuldade de inserção no mercado de trabalho com base na teoria do capital humano. Contudo, a evasão escolar precoce seja pela pouca atratividade da escola ou pela necessidade econômica e a dificuldade de se inserir e se manter no mercado de trabalho demonstra que este problema possui aspectos que extrapolam a qualificação da força de trabalho dos jovens.

Somente a educação não é suficiente para garantir a sua inserção no mercado de trabalho, mas sim crescimento econômico e geração de renda e emprego que possibilitem aos adultos a permanência de seus filhos na escola e não os obrigue a abandoná-la para compor a renda domiciliar. Outro ponto é uma maior igualdade por gênero em relação aos afazeres domésticos e cuidados de familiares que possa reduzir a sobrecarga atual sobre as mulheres jovens.

O principal objetivo desse trabalho é estimar as probabilidades de transição entre as situações de estudo, trabalho e inatividade dos jovens no Brasil no período recente. A maior novidade será considerar a população nem-nem desagregada segundo a situação de desemprego e inatividade. Para tal, serão utilizados os dados da PNAD Contínua (PNADC), praticamente inexplorados em estudos sobre os nem-nem no país.

Na próxima seção será desenvolvida uma resenha bibliográfica sobre os trabalhos relativos aos jovens nem-nem no Brasil. Em seguida, é apresentada a metodologia utilizada. A seção 4 é iniciada com um breve relato sobre a evolução dos nem-nem nos últimos anos, utilizando os cortes de sexo e faixa etária. Segue-se a parte principal do artigo com o cálculo das probabilidades de transição entre as várias situações de atividade, inatividade e estudo. O período analisado vai de 2012 a 2016, quando a economia passou por um processo de desaceleração e crise econômica. O texto é encerrado com as principais conclusões. 
10 Transições entre situações de atividade, inatividade e estudo dos jovens nem-nem no Brasil - 2012/2016

\section{Resenha dos estudos sobre os jovens nem-nem no Brasil}

O objetivo desta seção é fazer uma resenha sobre os trabalhos publicados sobre a situação dos jovens nem-nem no Brasil. Os estudos sobre esses jovens estavam inicialmente inseridos dentro de uma análise mais ampla sobre a transição dos jovens entre a saída da escola e o mercado de trabalho. De acordo com o estudo de Pais (1995, 2001, apud Camarano et al, 2006), os modelos tradicionais de transição se caracterizam pela sequência linear e unidirecional das etapas de saída da escola, entrada no mercado de trabalho e saída de casa coincidindo com o casamento e nascimento do primeiro filho. Embora predominantes, esses modelos estão convivendo com novas trajetórias marcadas, muitas vezes, pela imprevisibilidade, não-linearidade e reversibilidade das etapas. No que concerne à transição escola-trabalho, é cada vez mais comum a combinação de atividades e situações características dos mundos jovem e adulto.

Por sua vez, Hasenbalg (2003 apud Camarano et al, 2006) considera que para os países desenvolvidos é realista assumir a entrada no mercado de trabalho após a conclusão da educação formal. Segundo o autor, "a norma é que os jovens façam trajetórias escolares prolongadas, cumprindo minimamente a educação compulsória estipulada". No Brasil e em outros países da América Latina, essa continuidade nem sempre se verifica devido à entrada precoce no mercado de trabalho e à conciliação ou superposição entre escola e trabalho.

Dentro deste contexto surgem as primeiras análises sobre os jovens nem-nem, que seriam aqueles que estariam com mais dificuldades nesta transição ou que a interromperam, buscando compreender as suas características.

De acordo com o Estatuto da Juventude ${ }^{4}$, para efeito de políticas públicas, são considerados jovens as pessoas entre 15 e 29 anos de idade. Contudo, existe uma dificuldade na conceituação da população jovem. Camarano et al (2004) trata desta dificuldade. Segundo os autores, a Assembleia Geral da ONU definiu juventude, pela primeira vez, em 1985 na ocasião do Ano Internacional da Juventude. Ao subscrever as diretrizes para as ações futuras e o acompanhamento desse subgrupo populacional, a Assembleia considerou como jovens as pessoas entre 15 e 24 anos de idade, sem prejuízo de outras definições de Estados membros.

A faixa etária escolhida seria baseada em fundamentos apropriados, tendo em vista que as entradas e saídas dessa fase coincidem com importantes períodos de transição no ciclo de vida. O limite inferior considera a idade em que as funções sexuais e reprodutivas já estão desenvolvidas, que diferenciam o adolescente da criança e repercutem na sua dinâmica física, biológica e psicológica. O limite superior refere-se ao momento em que os indivíduos normalmente concluem o ciclo da educação formal, normalmente entram no mercado de trabalho e constituem suas próprias famílias, caracterizando a transição para a fase adulta.

${ }^{4}$ Lei $\mathrm{N}^{o}$ 12.852, de 5 de agosto de 2013.

Econômica-Niterói, v. 21, n. 1, p. 6-43. Junho, 2019 
Os trabalhos exclusivamente sobre os jovens nem-nem no Brasil são relativamente recentes, tendo sido o de Camarano et al (2006) o primeiro a tratar especificamente deste tema. Estudos anteriores apresentavam informações sobre esses jovens dentro do contexto mais amplo de análise do mercado de trabalho dos jovens e sua inserção educacional e sobre como estava sendo feita a transição escola-trabalho dos jovens. Não havia um olhar específico.

Ao longo dos anos 1990 e início dos anos 2000, muitos estudos nacionais centravamse sobre o aumento da escolaridade dos jovens, resultando em uma maior proporção de jovens que somente estudavam ou que trabalhavam e estudavam, enquanto se reduzia a proporção daqueles que somente trabalhavam. Ressalta-se ainda que não havia, e em muitos casos ainda não há, uma faixa etária comum nos diferentes estudos acadêmicos. Somente a partir dos estudos de Camarano et al (2001) que se iniciou uma tentativa de fazer análises de acordo com as faixas etárias adotadas internacionalmente. Inicialmente, seus estudos focavam na faixa etária de 15 a 24 anos, tendo sido ampliada posteriormente para de 15 a 29 anos, em decorrência de padrões de comportamento dos jovens na transição para a fase adulta.

Outro ponto importante é que a maioria dos estudos trata especificamente os jovens que não trabalham, não estudam e nem procuram emprego, pois consideram que aqueles que estão à procura de emprego teriam feito a opção pelo trabalho, estando temporariamente fora do mercado de trabalho. Com esta opção, um estudo amplo com jovens nem-nem de acordo com os critérios internacionais (desocupados e inativos) ainda não havia sido realizado.

Leme e Wajnman (2000) apresentaram um estudo sobre a alocação do tempo dos adolescentes brasileiros de 12 a 19 anos entre o trabalho e o estudo entre os anos de 1981 e 1998 que jogou luz sobre a situação desses jovens, apesar do foco do trabalho ter sido o aumento do nível de escolaridade dos jovens e da proporção de jovens que trabalhavam e estudavam simultaneamente ao longo deste período.

Em relação aos jovens nem-nem, os resultados apontam que naquele período era mais provável esta condição para as mulheres, nas famílias com maior número de crianças, o que estaria associado ao maior tempo dedicado às tarefas domésticas e aos cuidados dos irmãos pequenos. Para as mulheres, uma diferença importante entre 1981 e 1996 foi a redução na probabilidade de não trabalhar nem estudar. Segundo as autoras, as variáveis macroeconômicas analisadas (taxa de crescimento do PIB, salário mínimo, taxa de desemprego, gastos com educação, tamanho relativo da coorte e taxa de urbanização) não tiveram impacto sobre a probabilidade de não trabalhar e não estudar.

Camarano et al (2001) apresentaram um estudo sobre a situação dos jovens de 15 a 24 anos no mercado de trabalho a partir das informações das PNADs em $1981 \mathrm{e} \mathrm{em}$ 1999, considerando sua situação de atividade e de frequência escolar, contemplando na análise os jovens na condição nem-nem. Este estudo também aponta para a redução da participação de mulheres neste grupo de jovens em todas as faixas etárias analisadas e um 
12 Transições entre situações de atividade, inatividade e estudo dos jovens nem-nem no Brasil - 2012/2016

aumento da participação entre os homens nas faixas etárias de 18 a 19 anos e de 20 a 24 anos e redução na faixa de 15 a 17 anos.

Entre os anos de 1981 e 1999, o percentual de jovens nem-nem de 15 a 24 anos passou de $9 \%$ para $12 \%$ para os homens e de $38 \%$ para $29 \%$ para as mulheres. Ao longo deste período, o destaque entre os jovens brasileiros foi o aumento na participação daqueles que somente estudam e dos que trabalham e estudam, enquanto houve redução dos jovens que somente trabalham.

Para o ano de 1999, os autores apontaram que quase metade dos homens nem-nem estavam procurando trabalho. Entre as mulheres seriam $22 \%$, mas com uma taxa crescente em relação à idade. A situação dos indivíduos na família era bastante diferenciada entre os sexos. Cerca de $80 \%$ dos jovens nem-nem homens eram filhos, com taxa decrescente com a idade. Contudo, $73 \%$ dos jovens de 20-24 anos ainda moravam com os seus pais. Entre as mulheres, $55 \%$ eram cônjuges e $11 \%$ eram chefes de família, portanto, já tinham formado as suas próprias famílias, sendo que a proporção cresce com a idade. Naquele ano, 16,5\% daquelas na condição nem-nem já tinham tido filhos.

O estudo de Camarano et al (2006) trata pela primeira vez especificamente dos jovens nem-nem no Brasil a partir de informações dos Censos Demográficos de 1980 e 2000, apontando se seria o caso de uma não transição ou uma transição negada a partir das vulnerabilidades e potencialidades advindas do contexto familiar. Os autores focam a análise nos jovens de 15 a 29 anos que nem trabalham, nem estudam e nem procuram trabalho, os inativos, pois consideram que aqueles que procuram trabalho já fizeram a opção pelo trabalho. Em 2000, eram cerca 8 milhões de jovens inativos, o que representava $17 \%$ dos jovens não inseridos nem no sistema educacional nem no mercado de trabalho.

Neste estudo foi utilizado um modelo de regressão logística para avaliar o impacto de algumas variáveis para essa condição dos jovens em 2000, presumindo que idade, sexo, cor/etnia, situação de domicílio, estado conjugal, posição no domicílio, posição social, tamanho das famílias e, no caso das mulheres, maternidade, poderiam exercer influência na ampliação ou restrição das possibilidades dos jovens. A família afeta a constituição identitária e social dos jovens, funcionando, para os autores, como agente promotor de potencialidades ou de acirramento da condição de vulnerabilidade.

Ao comparar a situação de atividade e de frequência escolar de jovens entre 1980 e 2000, um dos principais resultados apontados foi a forte redução da proporção de mulheres que nem estudavam, nem trabalhavam e nem procuravam emprego. Em 1980, quase metade das mulheres jovens estavam nesta condição, enquanto em 2000 havia se reduzido para pouco mais de um quarto, caindo mais em decorrência do aumento da participação feminina no mercado de trabalho e na frequência escolar. A proporção de homens jovens, por sua vez, permaneceu estável em torno de 7\% ao longo das duas décadas.

Os resultados apontam ainda que os jovens que não estudavam e não compunham a força de trabalho, em 2000, residiam principalmente na zona rural, eram de cor parda, com baixa escolaridade, inseridos em domicílios com maior número de crianças, com

Econômica-Niterói, v. 21, n. 1, p. 6-43. Junho, 2019 
renda baixa e chefe de menor escolaridade. A proporção de mulheres jovens que não estudavam e não trabalhavam era consideravelmente mais elevada que a dos homens. E, ainda, quase 3/4 delas já eram mães e 2/3 moravam com um parceiro. Para os autores, esses resultados permitiam concluir que a alocação do tempo dos jovens e, portanto, o processo de transição para a vida adulta apresenta um forte viés de gênero. De modo geral, os homens parecem mais vinculados ao mercado de trabalho e as mulheres ao estudo ou às tarefas domésticas.

Através de um modelo de regressão logística foram identificados fatores que contribuíram para que o jovem não estivesse estudando nem trabalhando. A análise considerou características de saúde e sócio demográficas do indivíduo, assim como as do domicílio em que se encontram, separadamente, para homens e mulheres. A variável que mostrou o maior impacto na probabilidade de o jovem estar nesta condição, para ambos os sexos, foi a de ser portador de algum tipo de paralisia física, sendo maior entre mulheres, pessoas mais velhas e menos educadas. Em contrapartida, entre as variáveis que mais contribuíram para os jovens não pertencerem a esta categoria destaca-se o número médio de pessoas com renda positiva, o que pode funcionar como uma proxy da renda domiciliar, e a escolaridade do indivíduo.

O estado conjugal, por sua vez, teve efeitos importantes, mas com sinais diferentes entre os sexos. Havia maiores chances de não estar estudando e estar fora do mercado de trabalho entre os homens solteiros e entre as mulheres casadas, independentemente do fato de a mulher ter filho ou não. Se a mãe jovem for solteira ou divorciada e tiver filho, a probabilidade de se encontrar nessa condição diminui, ou seja, é provável que a mãe que não vive com um companheiro trabalhe para sustentar do filho.

Para Camarano e Kanso (2012), a situação dos jovens de 15 a 29 anos que não trabalham, não estudam e não procuram trabalho em relação aos jovens com as demais situações de atividade e frequência escolar é preocupante, tendo em vista a vulnerabilidade à qual estão submetidos. As autoras analisaram as informações entre 2000 e 2010 e concluíram que para as mulheres, estado conjugal e maternidade são fatores que parecem associados à condição de não trabalhar e não estudar, o que determinaria uma transição para a vida adulta "diferenciada" por sexo.

As mulheres representam cerca de 7 a cada 10 jovens nesta situação. Cerca de $40 \%$ seriam cônjuges e $60 \%$ seriam mães em 2010. Entre os homens, a maioria era solteiro. Em termos de vulnerabilidade, esses jovens estavam inseridos em famílias cujo rendimento médio domiciliar per capita era o mais baixo dentre as famílias que tinham jovens nas outras categorias.

A condição nem-nem seria um mecanismo gerador de exclusão e desigualdade a longo prazo para Cardoso (2013), que assim como os demais autores considera como nemnem os jovens inativos. A maioria desses jovens possui baixa escolaridade, pertence a famílias pobres, cerca de $70 \%$ são mulheres, das quais aproximadamente $40 \%$ com filhos. A chance de retornar ao mercado de trabalho e/ou aos estudos é pequena, tendendo a 
14 Transições entre situações de atividade, inatividade e estudo dos jovens nem-nem no Brasil - 2012/2016

permanecer nesta situação. Segundo o autor, esta condição é resultado da conjunção de dois feixes de determinantes: de um lado, a inserção social dos jovens, que engloba a família, o sistema escolar e o mercado de trabalho, e de outro as trajetórias dos indivíduos.

Menezes-Filho et al (2013) analisam o aumento da proporção de jovens nem-nem entre 2003 e 2011 e questionam se a situação desses jovens é permanente ou transitória. O estudo foca também nos jovens inativos na faixa etária de 17 a 22 anos a partir dos microdados da Pesquisa Mensal de Emprego (PME) do IBGE em dois momentos, 2003-2004 e 2010-2011. A tendência de aumento da taxa de jovens inativos seria mais acentuada para os homens, de $9 \%$ em 2003 para 11\% em 2011, contudo o valor da taxa seria maior para as mulheres, $19 \%$ nos dois anos.

Para os autores, o crescimento da taxa de jovens inativos ao longo do período analisado, a despeito da melhora observada no mercado de trabalho para os trabalhadores em geral, inclusive para os jovens, ocorreu devido ao aumento da duração média dos jovens nesta situação. Porém, esta duração seria curta, com indícios de grande rotatividade dessa situação em relação ao mercado de trabalho. Esta seria uma condição temporária na maioria dos casos, durando mais tempo no caso dos jovens com ensino fundamental incompleto com duração bem maior do que aqueles que possuem níveis de escolaridade maiores.

Considerando-se o período de um ano, $42 \%$ dos jovens que estavam na condição nemnem na situação inicial permaneceram na mesma situação. Outros $42 \%$ passaram a ser só $\mathrm{PEA}^{5}, 10 \%$ só estudavam e $6 \%$ estudavam e eram da PEA. Daqueles que só estudavam, $13 \%$ passaram à condição nem-nem após um ano, quem só trabalhava, $12 \%$ e quem estudava e trabalhava, $6 \%$.

Neste sentido, como alegam os autores, a condição nem-nem-nem seria transitória para muitos jovens, principalmente para o mercado de trabalho. Em relação ao aumento da taxa de homens jovens inativos, os autores consideram que ela se deve ao aumento da duração média desses jovens nesta condição (de 2,4 meses em 2004 para 3 meses em 2010). No caso das mulheres, tanto a taxa de entrada na condição nem-nem quanto a duração média na mesma condição são maiores. Contudo, apesar de a taxa ser estável ao longo do tempo, há uma redução da taxa de entrada que compensa um movimento de aumento da duração média.

Por nível de escolaridade, os autores apontam que a taxa de inatividade era significativamente maior entre os menos escolarizados (com ensino fundamental incompleto) e o crescimento da proporção de jovens nem-nem inativos era também mais acentuado nesse grupo. Ressaltam as elevadas taxas de entrada e durações médias da condição nem-nem dos indivíduos com Ensino Fundamental incompleto, consistentemente maiores do que aquelas dos mais escolarizados.

\footnotetext{
${ }^{5}$ Neste caso, ser PEA significa que ou estava trabalhando ou estava procurando emprego. O jovem na condição nem-nem, nesse caso, é aquele que não estuda, não trabalha e nem procura emprego.
}

Econômica-Niterói, v. 21, n. 1, p. 6-43. Junho, 2019 
Eles relacionam a dificuldade escolar com a condição de inatividade dos jovens brasileiros. Para os autores, os jovens com 17 a 22 anos que não completaram o Ensino Fundamental estavam com um atraso escolar de no mínimo dois anos, abandonaram os estudos de forma crescente e, aqueles que o fizeram, permaneciam em média mais tempo fora do mercado de trabalho. Neste sentido, consideram que o atraso no sistema educacional pode ter relação com o fluxo de jovens para a condição nem-nem, que passa a constituir um grupo em condições de competição no mercado de trabalho muito desfavoráveis.

O estudo apresentado por Monteiro (2013) busca caracterizar também os jovens inativos, porém na faixa etária de 19 a 24 anos. Seriam 3,2 milhões ou 17\% dos jovens nesta condição. Os principais resultados apontam que a condição de nem-nem inativa é mais preponderante entre jovens com baixa escolaridade (cerca de 1 milhão possuem ensino fundamental incompleto) e de baixa renda (1,5 milhão vivem em família com renda de até 2 salários mínimos, em 2011). Quase metade dos jovens é representada por mulheres com filhos. Essas mulheres têm níveis de inatividade muito altos, mas sua participação no mercado de trabalho vem aumentando, ao mesmo tempo em que seu peso na população vem caindo devido à queda da fecundidade. A autora considera que ter um filho de menos de 1 ano é o principal fator que explicaria porque as mulheres, especialmente as mais pobres, estavam na condição nem-nem.

A autora mostra também que a inatividade havia crescido entre os homens no período 2001/2011, especialmente entre os que possuíam menor nível de escolaridade, indicando que os homens que estudam pouco estão se afastando do mercado de trabalho. Ressalta, ainda, o aumento da inatividade entre jovens com ensino médio, o que seria um dado preocupante tendo em vista que se trata do nível de ensino preponderante não só entre os jovens nem-nem inativos, mas entre os jovens como um todo, indicando que o aumento da escolaridade traz novos desafios.

Monteiro (2013) ainda revela que mulheres que têm um bebê e são pobres têm 10 pontos percentuais a mais de chance de estar na condição nem-nem do que mulheres que têm um bebê e não são pobres, o que poderia ser explicado tanto pela falta de creches públicas quanto pelo fato de que mulheres de domicílios pobres são em geral pouco educadas e por isso têm um custo de oportunidade menor de ficar em casa.

Cabanas et al (2014) analisaram a situação dos jovens de 15 a 24 anos entre as condições de estudo e trabalho no contexto de redução da taxa de desemprego e alto nível de atividade econômica do país. Apesar da melhora no mercado de trabalho de 2004 a 2013, a taxa de participação dos jovens na População Economicamente Ativa (ocupados ou desocupados) diminuiu, assim como dos jovens que estudam e trabalham. Por outro lado, verificaram um aumento na proporção dos jovens que somente estudam e dos jovens nem-nem inativos. Em relação aos determinantes dessas condições, os resultados do estudo mostram que, no geral, aumentos na renda dos jovens e dos adultos influenciam positivamente as probabilidades de estudo e negativamente de oferta de trabalho, porém esse resultado varia de acordo com características dos jovens e do domicílio. 
Os autores mostram que existe uma forte dependência dos jovens em relação à renda domiciliar, o que pode explicar em parte a recente queda na taxa de participação dos jovens no mercado de trabalho e crescimento daqueles que só estudam dados os incrementos salariais reais dos adultos no Brasil. Essa influência é ainda maior caso os pais estejam presentes no domicílio, ou caso os próprios jovens ou os pais tenham escolaridade maior.

Outro fator importante apresentado no estudo foi que o aumento na renda no período também para o grupo dos jovens torna o custo de oportunidade do estudo mais alto. Esse aumento leva à redução da participação exclusiva dos jovens na PEA, em favor da dedicação aos estudos.

Simulações com interações da renda do jovem com seu nível educacional mostra que os resultados diferem muito para jovens com formação no ensino fundamental ou médio. Entre aqueles sem o fundamental completo, um aumento da renda impacta na redução da participação na PEA e crescimento da dedicação exclusiva aos estudos, mas também na situação nem-nem inativa, o que evidencia a relação da baixa escolaridade com a situação nem-nem.

Por outro lado, entre os mais escolarizados, o aumento da renda representa a redução das probabilidades de participação exclusiva na PEA e da situação nem-nem inativa em favor das duas situações de estudos, especialmente aquela associada à participação no mercado de trabalho.

A renda domiciliar e a educação dos pais também proporcionariam condições para melhor qualificação dos filhos, que passam a se dedicar mais aos estudos mesmo com as pressões para ofertar trabalho, ou seja, os pais passam a cobrir o custo de oportunidade dos jovens trabalharem.

Outro aspecto observado pelos autores foi a influência positiva para o estudo quando existe a presença do adulto e/ou do idoso no domicílio. Além disso, há impacto negativo da presença de crianças sobre as probabilidades de não ser nem-nem inativo, acentuado no caso de haver mais crianças no domicílio, fato que pode ser explicado pela necessidade dos jovens cuidarem das crianças presentes não podendo estudar nem ofertar trabalho. A presença dos pais no domicílio tem efeitos positivos sobre as probabilidades de qualquer situação, relativamente aos nem-nem inativos, o que mostra a importante influência da estrutura familiar.

Ciríaco (2015) analisa os jovens nem-nem inativos de 18 a 25 anos com o objetivo de determinar os principais condicionantes da condição nem-nem no Brasil entre os anos de 2002 e 2012 através de um modelo logístico. Os resultados apontaram que ter outro jovem nem-nem com a mesma faixa de idade na família tende a aumentar em mais de 2/5 a probabilidade do jovem estar na condição nem-nem. Além disso, as variáveis de background familiar e escolaridade do jovem também foram apontadas como fundamentais na determinação da condição do jovem nem-nem, o que reforça a ideia de que uma conjuntura familiar favorável é primordial para redução das taxas de inatividade laboral e educacional entre os jovens. O estudo ainda aponta que a existência de idosos apo- 
sentados no meio familiar tende a aumentar a probabilidade do jovem estar na condição nem-nem.

Martins (2016) analisou os jovens nem-nem inativos de 18 a 24 anos no Estado do Rio de Janeiro entre 2004 e 2014, identificando também que as mulheres, especialmente as mães, e jovens com baixa escolaridade e renda possuem maiores chances de se encontrarem inativos. Entre 2004 e 2014, houve aumento da inatividade entre as mulheres sem filho e homens, enquanto decresceu das mulheres com filhos, o que indica a redução da importância da maternidade como justificativa para a inatividade. Isto decorre tanto pela redução da taxa de fecundidade como pela maior participação de mulheres com filho no mercado de trabalho.

Em termos de escolaridade, mais anos de estudo representam menor probabilidade do jovem estar inativo. Contudo, o estudo aponta que apesar do aumento dos anos de estudo dos jovens brasileiros, houve aumento na quantidade de jovens inativos em todos os níveis educacionais com exceção do ensino fundamental incompleto. Um nível de escolaridade maior teve efeito mais significativo para as mulheres do que para os homens saírem da inatividade, o que pode indicar que as políticas de aumento de atratividade da escola para os jovens parecem ser mais efetivas para as mulheres do que para os homens.

Em relação à renda, os jovens de domicílios que pertenciam ao primeiro e ao segundo quintos de renda tinham um percentual de inatividade mais alto do que os demais. Já quando se consideram as rendas advindas de programas sociais, o estudo aponta que, em 2014, o recebimento deste tipo de renda diminuiu a probabilidade das mulheres com filhos estarem inativas.

Simões et al (2013), em um relatório técnico do Ministério do Desenvolvimento Social, mostram um panorama para a totalidade dos jovens nem-nem de 16 a 24 anos entre 2001 e 2011, onde destacam a concentração de jovens nem-nem nas áreas urbanas. A taxa de jovens nem-nem também é mais elevada nas áreas rurais do que nas áreas urbanas. Há uma grande concentração de jovens nem-nem nas áreas urbanas não-metropolitanas. Em 2011, 55\% viviam em área urbana não metropolitana, 28\% em área urbana metropolitana e $17 \%$ em área rural.

As evidências empíricas levantadas nos trabalhos acima resenhados apontam que mulheres, com filho, baixa escolaridade e baixa renda têm efetivamente maior probabilidade de se tornar nem-nem. Ainda que tal população possa se renovar ao longo do tempo, o fenômeno dos jovens nem-nem no Brasil está atrelado à figura feminina em decorrência das diferenças existentes na divisão sexual do trabalho que atribui à mulher a maior parte dos cuidados com parentes e das tarefas domésticas. A mulher permanece como a principal responsável pelo trabalho reprodutivo o que torna a sua trajetória no sistema de ensino e no mercado de trabalho bem mais complexa do que para os homens.

A partir dessa resenha, verifica-se que com exceção do trabalho de Menezes-Filho et al (2013), há falta de estudos no Brasil que se concentrem nas probabilidades de transição entre as condições de atividade, inatividade e estudo da população jovem. Por outro lado, 
18 Transições entre situações de atividade, inatividade e estudo dos jovens nem-nem no Brasil - 2012/2016

aquele estudo utilizou uma fonte de dados restrita a apenas seis regiões metropolitanas (PME) com informações até 2011. Tal fato justifica a utilização do modelo que será apresentado neste artigo que, além de desagregar os jovens nem-nem nos dois grupos de inativos e desocupados, analisa o período recente de 2012 a 2016, a partir dos novos dados da PNAD Contínua, cobrindo, portanto, todo o país.

\section{Metodologia Utilizada para as a Estimativa das Matrizes de Transi- ção}

As matrizes de transição são muito importantes para estimar probabilidades de permanência ou de mudança no status da unidade de análise em relação a um determinado fenômeno de interesse. Cadeias de Markov são muito utilizadas para montar essas matrizes e estimar probabilidades de transição. Entretanto também é possível estimar probabilidades de transição por meio de dados longitudinais, ou seja, em situações onde a informação relativa ao status de interesse em dois momentos distintos está disponível.

No caso desse estudo, informações sobre o status relativo à situação de atividade e frequência escolar em dois ou mais momentos distintos estão disponíveis na PNADC, que é uma pesquisa amostral em nível nacional que utiliza um esquema de rotação em sua amostra. Esse esquema de rotação permite que haja uma sobreposição parcial de sua amostra, ou seja, que parte dos domicílios em uma determinada ocasião sejam os mesmos que participam de uma ocasião anterior.

As informações dos moradores desses domicílios repetidos podem ser utilizadas em estudos longitudinais, desde que o morador tenha respondido nas ocasiões de interesse do estudo. Entretanto, como a pesquisa é amostral e como muitos desses moradores não responderam à todas as ocasiões de interesse, é necessário fazer um tratamento nos pesos amostrais, de forma a que esses tornem a amostra de respondentes representativa da população. A seguir é apresentado o trabalho realizado para tratar os pesos amostrais da PNADC.

Em análises longitudinais com dados de pesquisas por amostragem probabilística apenas as unidades respondentes em todas as ocasiões do escopo da análise podem ser utilizadas. Devido à exclusão das unidades não respondentes em pelo menos uma das ocasiões e da possível introdução de viés nas estimativas, se faz necessária a adoção de uma metodologia para tratar os pesos amostrais originais. Os pesos amostrais resultantes desse tratamento são denominados de pesos longitudinais.

A PNADC é uma pesquisa trimestral que possui um plano amostral complexo, composto por estratificação, conglomeração e probabilidade proporcional ao tamanho nos mecanismos de seleção de sua amostra. Além disso, emprega um esquema de rotação 1-2 (5), no qual um domicílio que é sorteado para compor a amostra participa da pesquisa em um mês e descansa por dois meses, repetindo esse processo por cinco vezes, quando

Econômica-Niterói, v. 21, n. 1, p. 6-43. Junho, 2019 
o domicílio é retirado definitivamente da amostra. Esse esquema de rotação permite a utilização dos dados da pesquisa para análises longitudinais no nível do indivíduo, pois sobrepõe 80

O primeiro passo foi selecionar a ocasião de referência da análise longitudinal. As análises serão compostas por apenas duas ocasiões, trimestre inicial e o trimestre seguinte, a opção foi pela ocasião inicial. A ocasião de referência tem como função fornecer o peso base e as variáveis utilizadas nos procedimentos de correção da não resposta.

Devido ao fato da PNADC não disponibilizar um identificador ${ }^{6}$ que permita a união das informações das pessoas em ocasiões distintas da pesquisa foi necessário empregar um método de pareamento por meio de critérios sociodemográficos. Procedimento semelhante ao adotado por Ribas (2005) e Rojas (2014) com dados da Pesquisa Mensal de Emprego (PME). Os critérios sociodemográficos utilizados foram:

- Domicílio, número de ordem, posição no domicílio, sexo e data de nascimento idênticos;

- Domicílio, número de ordem, sexo e data de nascimento idênticos;

- Domicílio, posição no domicílio, sexo e data de nascimento idênticos;

- Domicílio, sexo e data de nascimento idênticos.

Após o pareamento iniciou-se o tratamento da não resposta, que foi dividido em duas etapas. Na primeira, foram tratados os casos daqueles que não responderam em nenhuma das duas ocasiões de interesse, para isso foi empregado um procedimento de calibração. $\mathrm{Na}$ segunda foram tratados por meio de modelagem os casos daqueles que responderam na ocasião inicial, mas não responderam na segunda ocasião. A figura 1 apresenta um modelo de como as técnicas de modelagem e de calibração foram empregadas na correção da não-resposta.

$\mathrm{O}$ primeiro passo para tratar os casos daqueles que não responderam nenhuma das duas ocasiões foi selecionar o peso amostral base, dado que a PNADC divulga dois pesos. A opção foi pelo peso não calibrado (v1027). Em seguida foi aplicado uma correção desse peso em função da quantidade de grupos rotacionais utilizados na análise, no caso foram utilizados 4 dos 5 grupos rotacionais possíveis. A seguir foi empregada a calibração com o objetivo de tratar o viés de disponibilidade (Vasconcelos; Silva, 2005), fenômeno muito comum em pesquisas domiciliares e que segundo os autores se caracteriza pela sobre-representação na amostra coletada de idosos e mulheres, com a consequente subrepresentação de jovens e homens. O método de calibração aplicado foi o de ranking (Deville; Särndall; Sautory, 1993) que se caracteriza por ajustar os pesos amostrais em

\footnotetext{
${ }^{6} \mathrm{O}$ IBGE futuramente disponibilizará um identificador nas bases de dados da PNADC que permitirá o pareamento direto.
} 
20 Transições entre situações de atividade, inatividade e estudo dos jovens nem-nem no Brasil - 2012/2016

Figura 1 - Modelo das técnicas de modelagem e de calibração na correção da não-resposta

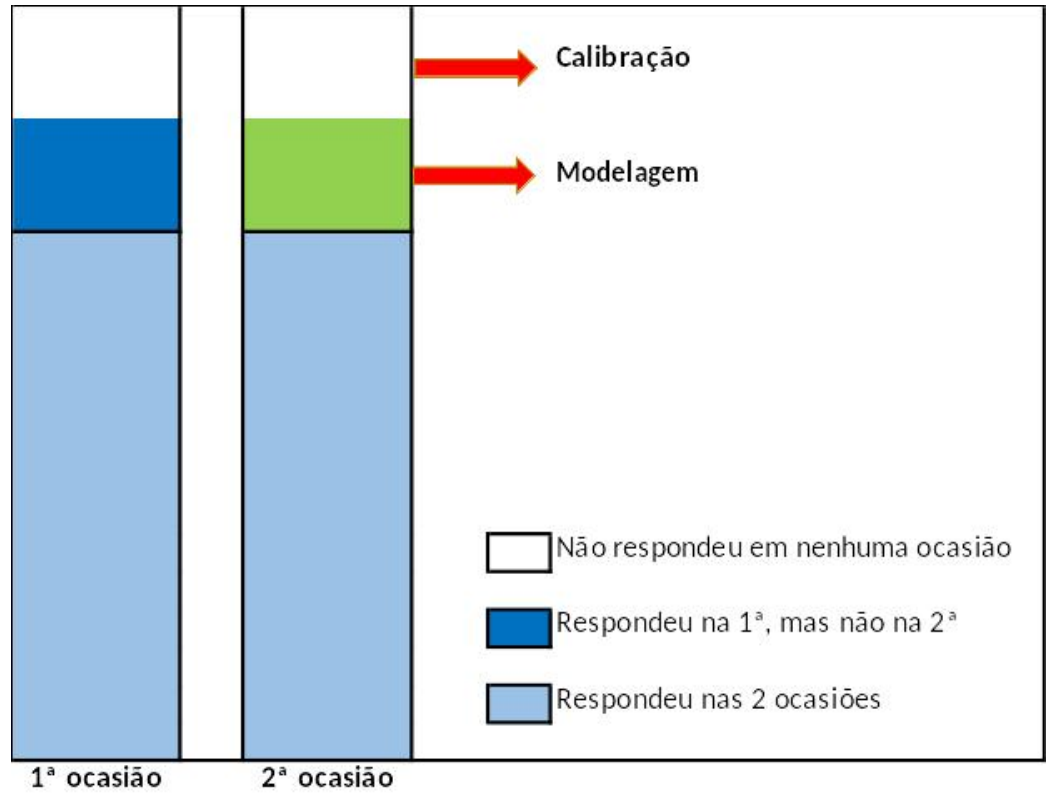

função das frequências marginais das variáveis auxiliares. Foram utilizadas duas informações auxiliares nesse procedimento, os totais populacionais das cinco grandes regiões geográficas segundo sexo e grupos etários, e o total populacional dos pós-estratos utilizados pelo IBGE em seu procedimento de pós-estratificação da PNADC. Os pesos obtidos após esse processo foram denominados de peso de referência e denotados por $w_{r e f}$.

A etapa seguinte foi tratar a não resposta daqueles que participaram de apenas da ocasião inicial dos escopos de análise longitudinal, para isso foi empregada uma técnica de modelagem (propensity score), derivada da regressão logística, com o objetivo de estimar a propensão dos indivíduos em participar da pesquisa. O nível de significância considerado foi de 0,05. As variáveis utilizadas na modelagem são apresentadas no Quadro 1, sendo que a única variável que não foi considerada significativa em nenhum dos dois modelos foi raça/cor, resultado semelhante ao obtido por Teixeira Junior (2015), com dados da PME.

Obtidas as propensões de resposta, foram calculados os fatores de ajuste, que nada mais são do que o inverso da propensão de resposta $f_{a j}=\frac{1}{\hat{\theta}_{(j, c \mid i)}}$. Os pesos longitudinais, por sua vez, são obtidos pela multiplicação do peso calibrado $w_{\text {ref }}$ pelo fator de ajuste $w_{\text {long }}=\frac{1}{\hat{\theta}_{(j, c \mid i)}} * w_{\text {ref }}$.

Para finalizar o procedimento de tratamento, os pesos longitudinais foram novamente calibrados, dessa vez com o objetivo de que os totais populacionais da análise coincidam com os totais populacionais da população analisada (de 15 a 29 anos de idade) dos pósestratos da PNADC utilizados pelo IBGE.

Econômica-Niterói, v. 21, n. 1, p. 6-43. Junho, 2019 
Quadro 1 - Variáveis explicativas e suas respectivas categorias

\begin{tabular}{|c|c|c|c|c|c|}
\hline Variáveis & Categ orias & Variáveis & Categ orias & Variáveis & Categorias \\
\hline Área & $\begin{array}{l}\text { RM da capital } \\
\text { Demais mun icípios da UF }\end{array}$ & \multirow[t]{2}{*}{ Faixa etária } & $\begin{array}{l}\text { Menos de } 30 \text { anos; } \\
\text { De } 30 \text { a } 59 \text { anos; }\end{array}$ & Frequenta escola & $\begin{array}{l}\text { Sim; } \\
\text { Não. }\end{array}$ \\
\hline \multirow{3}{*}{$\begin{array}{l}\text { Nível de } \\
\text { instrução }\end{array}$} & Até fundamental incompleto; & & 60 anos ou mais & \multirow{2}{*}{$\begin{array}{l}\mathrm{N}^{\circ} \text { de moradores } \\
\mathrm{c} / 14 \text { anos ou mais }\end{array}$} & 1 \\
\hline & $\begin{array}{l}\text { Fundamental completo; } \\
\text { Médio completo; }\end{array}$ & Raça/cor & $\begin{array}{l}\text { Branco; } \\
\text { Não branco }\end{array}$ & & $\begin{array}{l}2 \text { ou } 3 \\
4 \text { ou mais. }\end{array}$ \\
\hline & Superior comp leto. & \multirow{3}{*}{$\begin{array}{l}\text { Situação } \\
\text { ocupacional }\end{array}$} & Ocupados & \multirow{2}{*}{ Sexo } & Masculino; \\
\hline \multirow{2}{*}{$\begin{array}{l}\text { Posição no } \\
\text { domicílio }\end{array}$} & Responsável ou cônjuge; & & Desocupados & & Femin ino. \\
\hline & $\begin{array}{l}\text { Filho(a) } \\
\text { Outros parentes e não parentes. }\end{array}$ & & $\begin{array}{l}\text { Fora da PIA } \\
\text { Fora da força de trabalho }\end{array}$ & $\begin{array}{l}\text { Participa da força } \\
\text { de trabalho }\end{array}$ & $\begin{array}{l}\text { Sim; } \\
\text { Não. }\end{array}$ \\
\hline
\end{tabular}

As informações relativas ao plano amostral foram incorporadas nos procedimentos de estimação dos erros amostrais, mediante o pacote survey do R. Os coeficientes de variação (CV), seguindo recomendação do IBGE foram considerados bons até o nível de 15

Os dados trimestrais referentes à amostra da PNADC utilizada no estudo estão apresentados na Tabela 1 a seguir.

\section{Estimativas das matrizes de transição entre as situações de ativi- dade, inatividade e frequência escolar dos jovens nem-nem}

O objetivo dessa seção é analisar as transições entre as situações de atividade/inatividade e de frequência escolar dos jovens segundo o sexo, faixa etária, nível de escolaridade e regiões para avaliar em que medida os jovens nem-nem inativos e os desocupados permanecem nessa situação ou migram para as demais condições.

O estudo é realizado a partir da análise das informações das matrizes de transição de probabilidades com informações provenientes da PNADC-Pesquisa Nacional por Amostra de Domicílios Continua trimestral para os anos de 2012 a $2016^{7}$. Note-se que neste período há desaceleração da economia até 2014, seguida de forte crise em 2015 e 2016. Dessa forma será possível associar os movimentos encontrados nas transições ao comportamento da economia

Ao longo do estudo, observa-se que a presença de jovens inativos no conjunto de jovens nem-nem é significativo e persistente. Cerca de 7 a cada 10 jovens nem-nem estão nessa condição e mesmo em períodos de crise econômica o recuo dessa condição é muito pequeno. A desocupação existe em uma proporção menor, mas é mais volátil ao ciclo

\footnotetext{
${ }^{7}$ A opção pelos dados da PNAD Contínua no lugar da PME-Pesquisa Mensal de Emprego se deve principalmente pela atualidade da pesquisa, que possibilita analisar informações dos períodos anterior e posterior à crise econômica iniciada em meados de 2014. A série da PME se encerrou em 2015, enquanto a PNAD Contínua disponibilizava informações até meados de 2017 quando foram feitas as estimativas das matrizes de transição.
} 
22 Transições entre situações de atividade, inatividade e estudo dos jovens nem-nem no Brasil - 2012/2016

Tabela 1 - Número de jovens de 15 a 29 anos na bases de dados cross-sectional e na base de dados longitudinal - Brasil - 2012-2016

\begin{tabular}{|c|c|c|c|c|c|}
\hline \multirow{3}{*}{ Trimestre } & \multicolumn{2}{|c|}{$\begin{array}{c}\text { Base de dados cross- } \\
\text { sectional }\end{array}$} & \multicolumn{3}{|c|}{$\begin{array}{l}\text { Base da dados Longitudinal } \\
\text { (Apenas pessoas pareadas) }\end{array}$} \\
\hline & \multirow[b]{2}{*}{ Amostra } & \multirow[b]{2}{*}{ Expandido } & \multirow[b]{2}{*}{ Amostra } & \multicolumn{2}{|c|}{ Expandido } \\
\hline & & & & $\begin{array}{l}\text { Peso do } \\
\text { IBGE }\end{array}$ & $\begin{array}{c}\text { Peso } \\
\text { Iongitudinal }\end{array}$ \\
\hline $1^{\circ}$ Trimestre/2012 & 143.177 & 49.646 .116 & 87.601 & 30.896 .820 & 49.646 .116 \\
\hline $2^{\circ}$ Trimestre/2012 & 142.083 & 49.419 .426 & 91.588 & 31.864 .984 & 49.419 .426 \\
\hline $3^{\circ}$ Trimestre/2012 & 140.185 & 49.169 .362 & 90.760 & 31.877 .428 & 49.169 .362 \\
\hline $4^{\circ}$ Trimestre/2012 & 137.933 & 48.942 .573 & 89.219 & 31.838 .506 & 48.942 .573 \\
\hline $1^{\circ}$ Trimestre $/ 2013$ & 140.148 & 48.896 .170 & 90.507 & 31.730 .285 & 48.896 .170 \\
\hline $2^{\circ}$ Trimestre $/ 2013$ & 141.437 & 48.609 .225 & 89.376 & 31.101 .469 & 48.609 .225 \\
\hline $3^{\circ}$ Trimestre/2013 & 141.387 & 48.768 .482 & 90.495 & 31.439 .530 & 48.768 .482 \\
\hline $4^{\circ}$ Trimestre $/ 2013$ & 139.932 & 48.599 .007 & 89.557 & 31.486 .760 & 48.599 .007 \\
\hline $1^{\circ}$ Trimestre/2014 & 140.156 & 48.596 .382 & 90.131 & 31.779 .482 & 48.596 .382 \\
\hline $2^{\circ}$ Trimestre/2014 & 138.946 & 48.537 .023 & 90.154 & 31.883 .834 & 48.537 .023 \\
\hline $3^{\circ}$ Trimestre/2014 & 139.379 & 48.475 .004 & 89.550 & 31.655 .994 & 48.475 .004 \\
\hline $4^{\circ}$ Trimestre/2014 & 138.049 & 48.265 .234 & 88.302 & 31.129 .394 & 48.265 .234 \\
\hline $1^{\circ}$ Trimestre/2015 & 136.933 & 48.221 .225 & 89.077 & 31.860 .454 & 48.221 .225 \\
\hline $2^{\circ}$ Trimestre $/ 2015$ & 136.736 & 48.148 .516 & 89.157 & 31.703 .705 & 48.148 .516 \\
\hline $3^{\circ}$ Trime stre $/ 2015$ & 136.324 & 48.128 .641 & 87.131 & 31.088 .300 & 48.128 .641 \\
\hline $4^{\circ}$ Trimestre/2015 & 133.990 & 48.369 .791 & 85.914 & 31.527 .095 & 48.369 .791 \\
\hline $1^{\circ}$ Trimestre/2016 & 134.598 & 48.177 .611 & 85.441 & 31.090 .324 & 48.177 .611 \\
\hline $2^{\circ}$ Trimestre/2016 & 135.570 & 48.393 .723 & 85.260 & 31.010 .267 & 48.393 .723 \\
\hline $3^{\circ}$ Trimestre/2016 & 136.369 & 48.494 .555 & 84.742 & 30.758 .671 & 48.494 .555 \\
\hline $4^{\circ}$ Trimestre/2016 & 135.337 & 48.396 .132 & 83.513 & 30.584 .506 & 48.396 .132 \\
\hline
\end{tabular}

Fonte: Elaboração própria a partir dos microdados da PNADC.

Econômica-Niterói, v. 21, n. 1, p. 6-43. Junho, 2019 


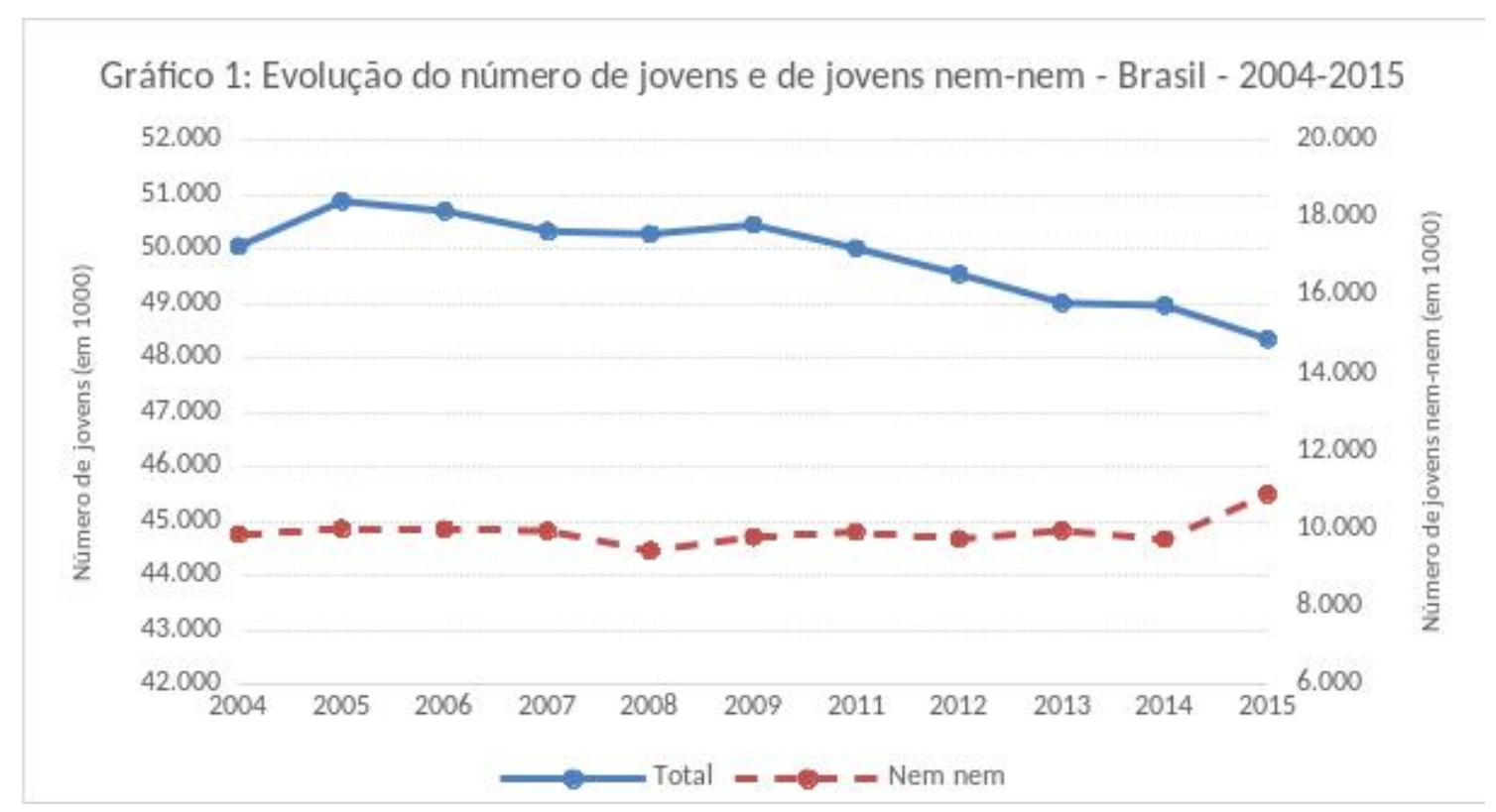

Fonte: Elaboração própria a partir dos microdados da PNAD.

econômico.

Antes de se passar ao estudo das matrizes de transição, serão apresentados alguns dados sobre a população nem-nem no Brasil nos últimos anos de modo a caracterizá-la e verificar as principais modificações ocorridas. Tendo em vista a inexistência de dados da PNADC antes de 2012, são utilizadas nessa apresentação informações da Pesquisa Nacional por Amostra de Domicílios (PNAD) no período 2004/2015, quando a PNAD foi descontinuada e substituída pela PNADC. Conforme pode ser verificado no Gráfico 1, enquanto o número total de jovens se reduziu por conta da transição demográfica do país, especialmente a partir de 2011, a população nem-nem permaneceu relativamente estável na maior parte do período, aumentando somente em 2015, ano de forte queda do PIB. Os jovens de 15/29 anos passaram de 50 para 48,3 milhões entre 2004 e 2015. Os jovens nem-nem aumentaram de 9,9 para 10,9 milhões no mesmo período.

Com isso, houve aumento da taxa de jovens nem-nem de $19,7 \%$ para $22,5 \%$ no período. Note-se, entretanto, que a maior parte do crescimento da taxa ocorreu entre 2014 e 2015. Outro fato notável é a taxa feminina, inicialmente quase o triplo da masculina, baixando para o dobro em 2015. Ao longo do período analisado, houve contínuo crescimento da taxa de jovens nem-nem entre os homens. Em 2015 ela atingia 15,4\% para os homens e 29,8\% para as mulheres. (Ver Gráfico 2).

Conforme mencionado anteriormente, a faixa etária para os jovens nem-nem utilizada neste estudo vai de 15 a 29 anos. Esta, por sua vez é desagregada em três faixas: 15/17; $18 / 24 ; 25 / 29$. A ideia de separar nessas três faixas deve-se ao fato dos jovens em cada 
24 Transições entre situações de atividade, inatividade e estudo dos jovens nem-nem no Brasil - 2012/2016

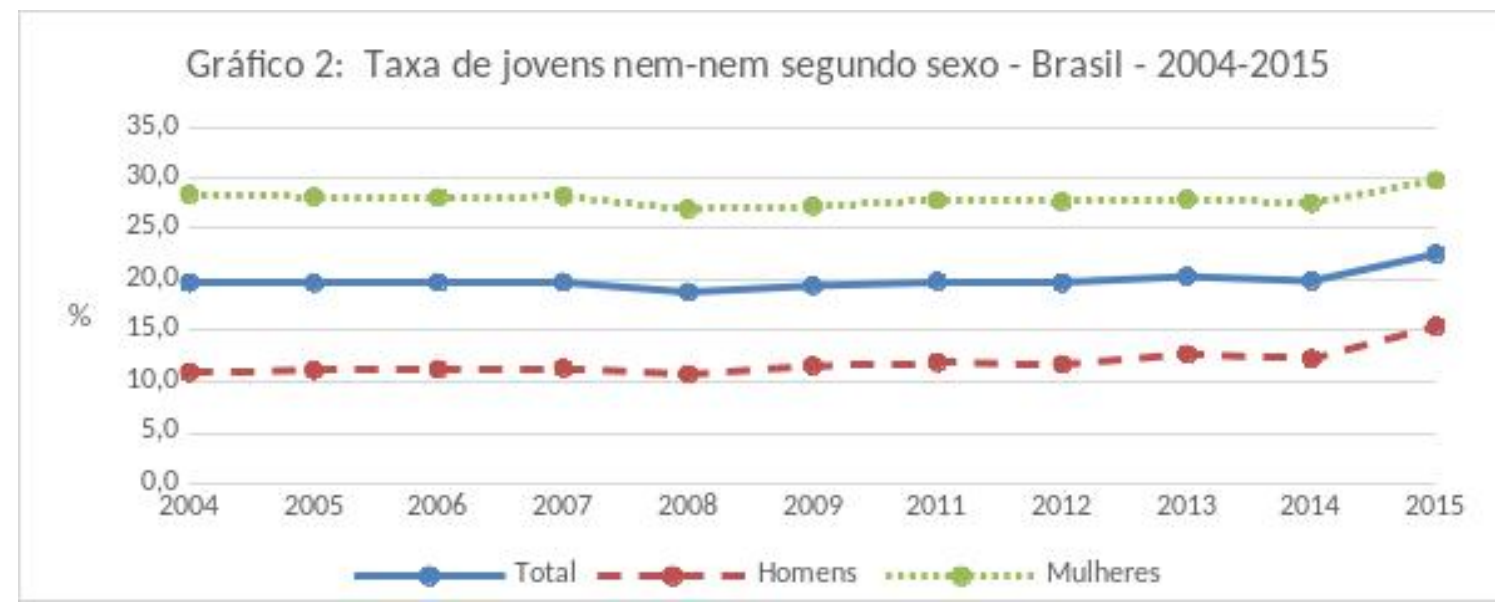

Fonte: Elaboração própria a partir dos microdados da PNAD.

uma delas estarem num momento diferenciado em relação aos estudos e à participação no mercado de trabalho. Aqueles de 15/17 anos deveriam preferencialmente estar estudando. O grupo 18/24 anos poderia estar combinando os estudos com a entrada no mercado de trabalho. Finalmente, seria esperado que os jovens adultos de 25/29 anos estivessem numa fase de finalização dos estudos e entrada maciça no mercado de trabalho.

Ao se fazer o corte pelo sexo e a faixa etária dos jovens nem-nem as diferenças são significativas. Entre 30 e $35 \%$ das jovens mulheres a partir de 18 anos encontram-se na situação de nem-nem, tendo, portanto, abandonado o estudo sem se inserir no mercado de trabalho. Cabe observar que a taxa de mulheres jovens nem-nem até 17 anos é bem mais baixa, tendo variado entre 10 e $12 \%$ no período. Já a taxa de homens nem-nem é sistematicamente inferior à feminina em todas as faixas etárias, porém com tendência de crescimento nos três grupos de idade. O dado mais negativo para os homens foi sua elevação em 2015, chegando a 20\% para aqueles entre 18 e 24 anos. (Ver Gráfico 3)

Grosso modo, a população nem-nem é composta por 30\% de desocupados e $70 \%$ de inativos. Considerando-se todo o período, tanto a taxa de nem-nem inativos quanto a de desocupados apresentaram tendência de elevação. Tal crescimento, entretanto foi muito mais elevado para os desocupados, especialmente no último ano. Em 2015, enquanto a taxa de jovens nem-nem era $22,5 \%$, a de inativos atingia $14,4 \%$, a de desocupados, $8,1 \%$. (Ver Gráfico 4)

Para que se tenha uma dimensão do que representam os grupos utilizados para o cálculo das matrizes de transição é apresentado a seguir no Gráfico 5 a distribuição dos jovens de 15/29 anos segundo a situação de estudo e trabalho. Conforme pode ser verificado, o grupo mais numeroso é o daqueles que somente trabalham que se manteve entre 43 e $45 \%$ na maior parte do período. Em 2015, entretanto, por conta da crise econômica, passaram para $41 \%$. Os que somente estudam vêm aumentando nos últimos anos, chegando a $25 \%$

Econômica-Niterói, v. 21, n. 1, p. 6-43. Junho, 2019 


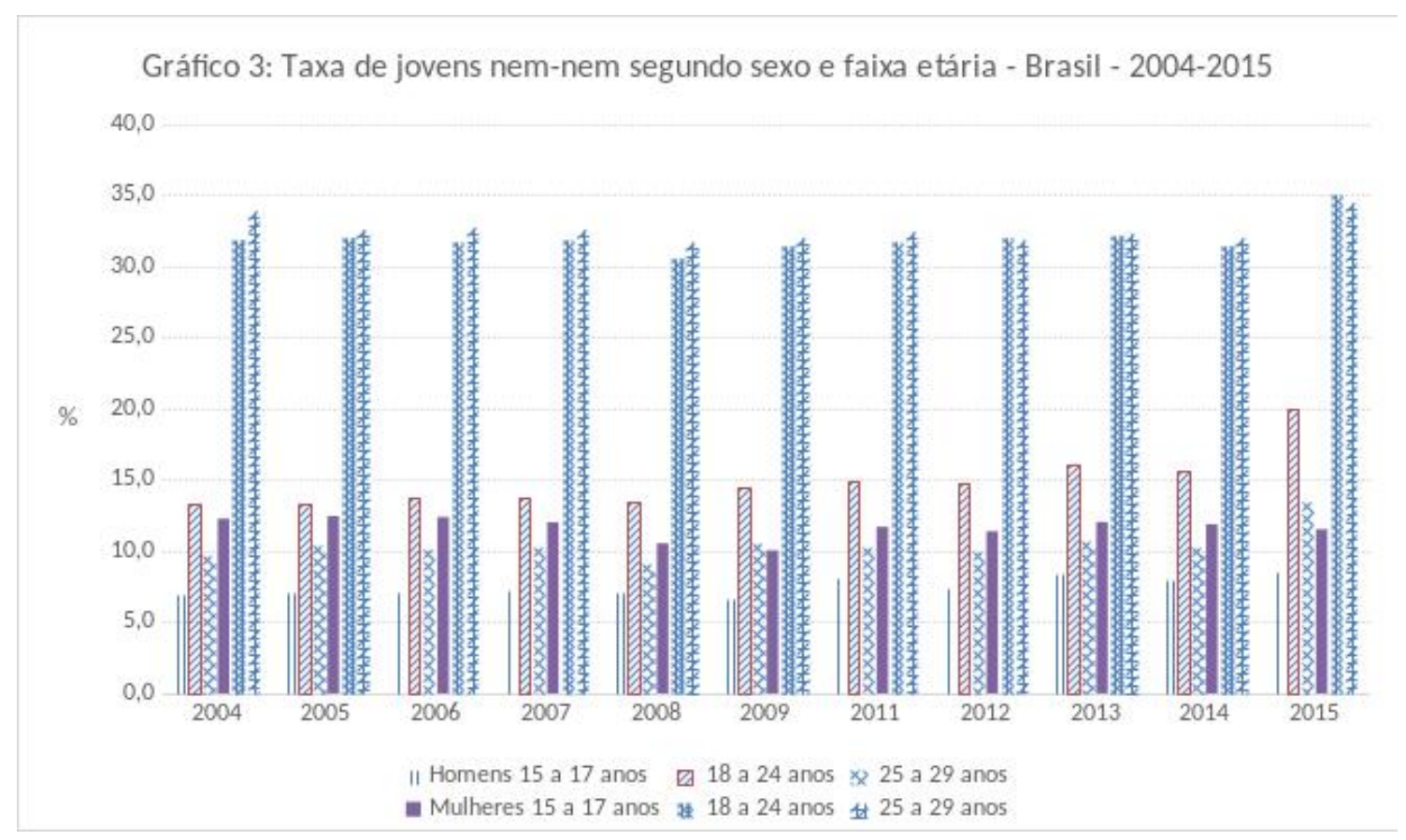

Fonte: Elaboração própria a partir dos microdados da PNAD.

Gráfico 4: Taxa de jovens nem-nem segundo condiçāo de atividade - Brasil - 20042015

25,0

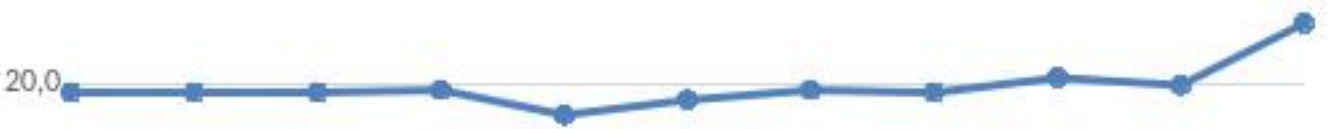

15,0

$\%$

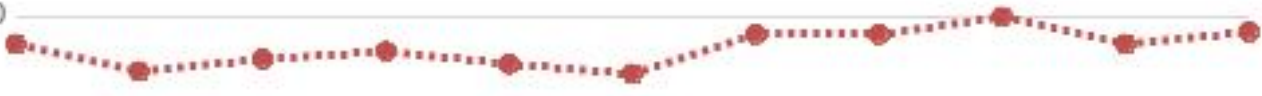

10,0

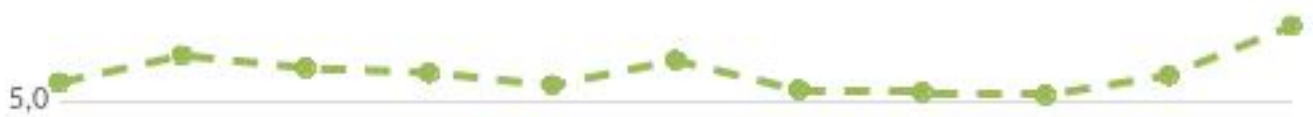

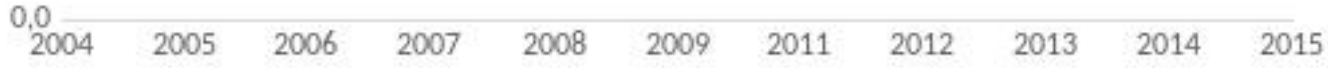

Fonte: Elaboração própria a partir dos microdados da PNAD.

Econômica-Niterói, v. 21, n. 1, p. 6-43. Junho, 2019 
26 Transições entre situações de atividade, inatividade e estudo dos jovens nem-nem no Brasil - 2012/2016

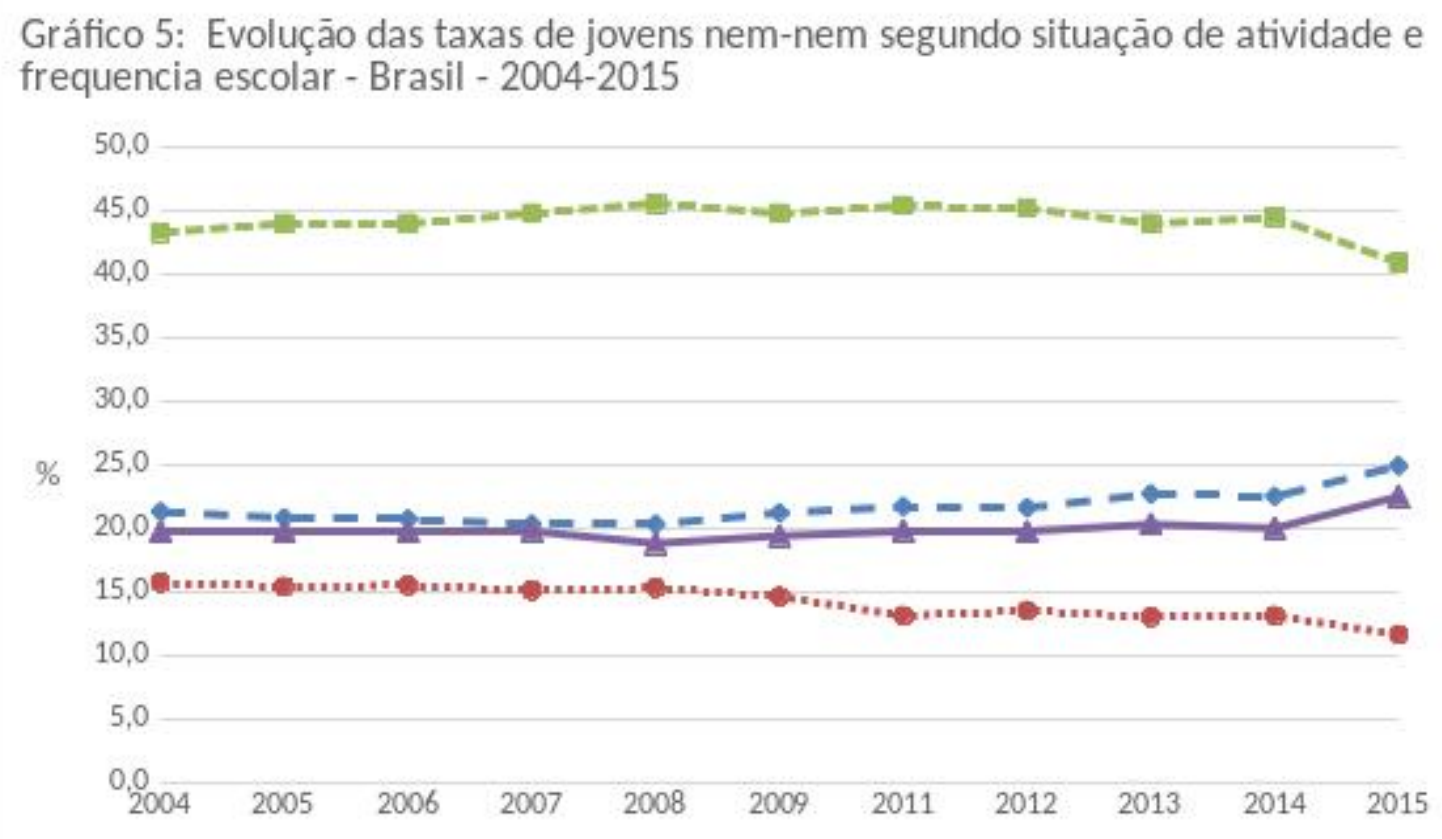

Fonte: Elaboração própria a partir dos microdados da PNAD.

no final do período. A combinação de estudo com trabalho vem recuando desde 2009, caindo ainda mais em 2015 quando ficou abaixo de 12\%. Já os jovens nem-nem, conforme já mencionado, sofreu um salto no último ano chegando a $22,5 \%$ dos jovens de $15 / 29$ anos, a maior parte composta por inativos.

Após essa breve caracterização da população nem-nem no país, são apresentadas a seguir as estimativas das matrizes de probabilidades de transição entre os anos de 2012 e 2016. Nas matrizes são consideradas as cinco situações possíveis para os jovens: somente estudar, somente trabalhar, estudar e trabalhar, nem-nem inativo e nem-nem desocupado.

A Tabela 2 apresenta as matrizes de probabilidades de transição do conjunto de jovens segundo situação de atividade e frequência escolar de 2012 a 2016. Os valores representam as médias das probabilidades de transição observadas nos quatro trimestres de cada $\mathrm{ano}^{8}$. Os jovens nem-nem foram desmembrados em inativos e desocupados de modo que a soma desses dois subgrupos representa a transição para a situação nem-nem. Esse desmembramento se justifica tendo em vista que um dos objetivos dessa análise é avaliar a migração de jovens dentro da própria situação nem-nem.

A maioria dos jovens tende a permanecer na mesma situação de atividade e frequência escolar, particularmente os que estão inseridos no sistema educacional ou no mercado de

\footnotetext{
${ }^{8}$ Embora possa haver efeitos sazonais nas transições dentro de um ano essa questão não faz parte dos objetivos do artigo.
}

Econômica-Niterói, v. 21, n. 1, p. 6-43. Junho, 2019 
Tabela 2 - Matrizes de probabilidades de transição dos jovens de 15 a 29 anos segundo situação de atividade e frequência escolar (\%) - médias anuais dos trimestres - Brasil - 2012-2016

\begin{tabular}{|c|c|c|c|c|c|}
\hline \multicolumn{6}{|c|}{2012} \\
\hline \multirow{2}{*}{ Situação inicial } & \multicolumn{5}{|c|}{ Situação final } \\
\hline & Estuda e Trabalha & Somente Estuda & Somente Trabalha & Nem-nem inativo & Nem-nem desocupado \\
\hline Estuda e Trabalha & 64,9 & 16,8 & 15,2 & 1,9 & 1,3 \\
\hline Somente Estuda & 10,1 & 80,3 & 2,4 & 5,3 & 2 \\
\hline Somente Trabalha & 6,1 & 1,7 & 81,1 & 7 & 4,2 \\
\hline Nem-nem inativo & 1,8 & 10,5 & 16,5 & 62,2 & 8,9 \\
\hline Nem-nem desocupado & 2,8 & 6,8 & 33,2 & 20,8 & 36,4 \\
\hline \multicolumn{6}{|c|}{2013} \\
\hline \multirow{2}{*}{ Situação inicial } & \multicolumn{5}{|c|}{ Situação final } \\
\hline & Estuda e Trabalha & Somente Estuda & Somente Trabalha & Nem-nem inativo & Nem-nem desocupado \\
\hline Estuda e Trabalha & 63,1 & 15,4 & 17,9 & 2,2 & 1,4 \\
\hline Somente Estuda & 9,9 & 78,8 & 3,0 & 6,3 & 2,0 \\
\hline Somente Trabalha & 4,4 & 1,2 & 84,6 & 5,9 & 3,9 \\
\hline Nem-nem inativo & 1,5 & 7,5 & 17,0 & 64,9 & 9,2 \\
\hline Nem-nem desocupado & 2,6 & 5,7 & 34,0 & 23,1 & 34,6 \\
\hline \multicolumn{6}{|c|}{2014} \\
\hline \multirow{2}{*}{ Situação inicial } & \multicolumn{5}{|c|}{ Situação final } \\
\hline & Estuda e Trabalha & Somente Estuda & Somente Trabalha & Nem-nem inativo & Nem-nem desocupado \\
\hline Estuda e Trabalha & 64,6 & 14,7 & 17,4 & 2,0 & 1,3 \\
\hline Somente Estuda & 8,9 & 80,1 & 2,7 & 6,0 & 2,2 \\
\hline Somente Trabalha & 4,1 & 1,1 & 85,3 & 5,7 & 3,9 \\
\hline Nem-nem inativo & 1,3 & 7,1 & 16,2 & 65,3 & 10,0 \\
\hline Nem-nem desocupado & 2,3 & 5,5 & 33,2 & 21,9 & 37,0 \\
\hline \multicolumn{6}{|c|}{2015} \\
\hline \multirow{2}{*}{ Situação inicial } & \multicolumn{5}{|c|}{ Situação final } \\
\hline & Estuda e Trabalha & Somente Estuda & Somente Trabalha & Nem-nem inativo & Nem-nem desocupado \\
\hline Estuda e Trabalha & 65,0 & 16,0 & 15,6 & 1,8 & 1,7 \\
\hline Somente Estuda & 8,4 & 81,1 & 2,2 & 5,7 & 2,6 \\
\hline Somente Trabalha & 4,0 & 1,0 & 84,2 & 5,8 & 5,0 \\
\hline Nem-nem inativo & 1,0 & 7,2 & 15,3 & 64,2 & 12,3 \\
\hline Nem-nem desocupado & 1,6 & 5,4 & 29,8 & 21,0 & 42,1 \\
\hline \multicolumn{6}{|c|}{2016} \\
\hline \multirow{2}{*}{ Situação inicial } & \multicolumn{5}{|c|}{ Situação final } \\
\hline & Estuda e Trabalha & Somente Estuda & Somente Trabalha & Nem-nem inativo & Nem-nem desocupado \\
\hline Estuda e Trabalha & 64,6 & 16,2 & 15,5 & 1,9 & 1,8 \\
\hline Somente Estuda & 7,7 & 82,5 & 1,9 & 5,0 & 3,0 \\
\hline Somente Trabalha & 3,7 & 0,9 & 83,5 & 5,8 & 6,1 \\
\hline Nem-nem inativo & 1,1 & 6,6 & 14,1 & 63,8 & 14,4 \\
\hline Nem-nem desocupado & 1,5 & 5,1 & 26,6 & 20,0 & 46,7 \\
\hline
\end{tabular}

Fonte: Elaboração própria a partir da PNADC. 
28 Transições entre situações de atividade, inatividade e estudo dos jovens nem-nem no Brasil - 2012/2016

trabalho com probabilidade de permanência acima de $80 \%$. Dos jovens que estudam e trabalham e os nem-nem inativos cerca de $65 \%$ permanecem na mesma situação. A permanência nessas quatro condições manteve-se praticamente constante entre $2012 \mathrm{e}$ 2016.

São os jovens nem-nem desocupados que apresentam as menores probabilidades de permanência, mas com probabilidades crescentes no período, demonstrando a dificuldade de inserção de uma parcela de jovens no mercado de trabalho em decorrência da crise econômica iniciada no final de 2014. Nesse período, a taxa de permanência dos desocupados passou de 34,6\% em 2013 para 46,7\% em 2016. Ao mesmo tempo, houve redução das probabilidades de transição dos jovens para a situação de somente trabalhar em 2015 e em 2016.

Os jovens que somente estudam ou que estudam e trabalham apresentaram as menores probabilidades de passarem para a situação nem-nem, seja inativa ou desocupada. A presença na escola contribuiria para que o jovem não se transforme em nem-nem. Por sua vez, os jovens que somente trabalham apresentam maiores chances de ser nem-nem do que os que estão no sistema educacional, principalmente por conta da alta rotatividade dos jovens no mercado de trabalho.

Entre os jovens nem-nem inativos cerca de 6 em cada 10 permaneceram na mesma situação, 25\% migram para a População Economicamente Ativa como ocupado ou desocupado. Desmembrando o período em análise em duas partes, observa-se que entre 2012 e 2014 cerca de $17 \%$ migraram para somente trabalhar, recuando para $15 \%$ em 2015 e para 14\% em 2016, fato que deve estar associado ao aprofundamento da crise econômica nesses dois anos. Ao mesmo tempo, a transição dos jovens inativos para a situação de desocupação cresceu. Entre 2012 e 2014, em torno de $9 \%$ a $10 \%$ dos jovens inativos tornaram-se desocupados, em 2015 aumentou para 12\% e em 2016 para 14\%. Apenas $7 \%$ desses jovens migraram para somente estudar e menos de $2 \%$ para estudar e trabalhar.

A situação nem-nem desocupada seria a mais transitória dentre as situações analisadas com somente 4 a cada 10 jovens permanecendo nessa situação de um trimestre para o outro, tornando as probabilidades de transição para outras situações mais elevadas. Cerca de $30 \%$ dos jovens desocupados migraram para a situação somente trabalhar. Entre 2012 e 2014, eram em torno de $33 \%$, recuando para $30 \%$ em 2015 e para $27 \%$ em 2016, movimento mais uma vez associado à crise econômica. Cerca de $20 \%$ transitaram para a inatividade, cerca de 5\% para somente estudar e apenas $2 \%$ para estudar e trabalhar.

A análise também pode ser realizada em sentido inverso para avaliar em que medida os jovens que estavam em outras situações de atividade e frequência escolar migraram para a inatividade ou para a desocupação.

Os jovens que mais migraram para a situação de inatividade foram os que estavam desocupados sem estudar (nem-nem desocupado). Em 2013, 23\% dos jovens que estavam nessa situação inicial transitaram para situação de inativo que não estuda (nem-nem inativo), mantendo-se próximo a $21 \%$ nos demais anos, demonstrando uma certa constân-

Econômica-Niterói, v. 21, n. 1, p. 6-43. Junho, 2019 
cia nessa transição. Dentre os demais jovens, cerca de $6 \%$ dos que somente trabalham e dos que somente estudam tornaram-se nem-nem inativos. Apenas $2 \%$ dos que estudam e trabalham fizeram o mesmo tipo de migração.

Por sua vez, foram os jovens inativos os que mais migraram para a situação de desocupação com uma taxa crescente ao longo do período em análise. Foram 9\% em 2012, em 2014 havia aumentado para 10\%, chegando em 2016 a 14\%. Dentre os jovens nas demais situações, $4 \%$ eram provenientes do mercado de trabalho até 2014 , aumentando no período posterior e chegando a $6 \%$ em 2016. Cerca de 2 a $3 \%$ migraram do sistema de ensino e apenas $1,5 \%$ estudavam e trabalhavam anteriormente.

Portanto, a permanência na inatividade revela-se muito mais duradoura do que na desocupação. Motivos familiares, econômicos e sociais podem explicar tal fato. Os jovens que conseguem sair dessa situação transitam principalmente para a desocupação na busca de um emprego. Entretanto, existe também uma parcela maior de jovens desocupados que fazem o caminho inverso em direção à inatividade. Existe uma forte sinergia estre as duas situações nem-nem.

A proporção de jovens nem-nem desocupados que migra para a inatividade costuma ser maior do que o inverso. Entre 2012 e 2014, era mais que o dobro. Entre 2014 e 2016, o movimento da inatividade para a desocupação se incrementou, enquanto da desocupação para a inatividade apresentou uma pequena queda, ambos como reflexo das dificuldades da economia.

O movimento de desocupação para inatividade pode ser interpretado como um tipo de desalento, já que o jovem tenta se inserir no mercado de trabalho, mas devido às dificuldades desiste e caminha para a inatividade. Por sua vez, da inatividade para a desocupação, que se acirra em momentos de crise, sinaliza a necessidade econômica pela busca de uma colocação no mercado de trabalho.

Analisando as informações das matrizes de probabilidades de transição por sexo, observam-se diferenças relevantes. As Tabelas 3 e 4 apresentam as estimativas das probabilidades para homens e mulheres jovens, respectivamente.

As diferenças por sexo surgem a partir da análise de permanência nas situações de atividade e frequência escolar. Os homens apresentam as maiores probabilidades de permanência em somente trabalhar, cerca de $85 \%$, seguidas de somente estudar, $80 \%$ e estudar e trabalhar, $65 \%$. As duas situações nem-nem apresentaram as menores probabilidades de permanência. Cerca de 50\% dos homens nem-nem permaneceram na inatividade, enquanto na desocupação eram 35\% entre 2012 e 2014, tendo saltado para $41 \%$ em 2015 e $46 \%$ em 2016.

No caso das mulheres, as situações de somente trabalhar e somente estudar também foram as que apresentaram as maiores probabilidades de permanência, ambas com cerca de $80 \%$. Em seguida estava a situação nem-nem inativa com cerca de $70 \%$, muito superior aos cerca de $50 \%$ dos homens nem-nem que permanecem inativos. No caso das mulheres, 
30 Transições entre situações de atividade, inatividade e estudo dos jovens nem-nem no Brasil - 2012/2016

estudar e trabalhar figura na quarta posição com cerca de $65 \%$ de permanência e, por último, a nem-nem desocupada com cerca de $40 \%$ entre 2012 e 2014, aumentando para $43 \%$ em 2015 e $47 \%$ em 2016. As mulheres possuíam probabilidades de permanência em somente estudar e na inatividade superiores às dos homens, inferiores em somente trabalhar e semelhantes em estudar e trabalhar e na desocupação.

Por faixa etária, a probabilidade de permanência na inatividade masculina era semelhante em todas as faixas etárias, próxima à 50\%, mantendo-se nesse patamar entre 2012 e 2016. Entretanto, na desocupação a probabilidade de permanência era maior entre os jovens de 18 a 24 anos e de 25 a 29 anos do que de 15 a 17 anos. No final do período, essa diferença entre as faixas etárias aumentou em comparação com o período anterior, pois as probabilidades de permanência cresceram mais nas duas faixas mais velhas do que na faixa mais nova. Assim, entre 2012 e 2016, as probabilidades de permanência no desemprego passaram de $30 \%$ para $31 \%$ entre os jovens de 15 a 17 anos, de $35 \%$ para $47 \%$ de 18 a 24 anos e de $37 \%$ para $45 \%$ de 25 a 29 anos.

Entre as mulheres, a probabilidade de permanência na inatividade era mais elevada do que a dos homens e crescentes com a faixa etária. Ela se situava em torno de $65 \%$ nas jovens entre 15 e 17 anos, $70 \%$ entre 18 e 24 anos e $75 \%$ entre 25 e 29 anos. Na desocupação, as jovens de 18 a 24 anos e de 25 a 29 anos apresentaram as maiores probabilidades de permanência. Em 2013, era da ordem $36 \%$ em ambas as faixas, tendo crescido substancialmente no período, chegando em 2016 com uma probabilidade de permanência na desocupação de $49 \%$ entre as jovens de 18 a 24 anos e de $46 \%$ de 25 a 29 anos.

As diferenças nas probabilidades de transição por sexo são significativas. Conforme mencionado acima, cerca de metade dos homens inativos permaneceu na mesma situação. Dentre os que migraram no período pré-crise, cerca de $25 \%$ dos homens começaram a trabalhar, em torno de $13 \%$ ficaram desocupados, $10 \%$ somente estudaram e apenas $2 \%$ estudaram e trabalharam. Com o início da crise econômica, houve redução das probabilidades dos homens que migraram para somente trabalhar e ao mesmo tempo houve aumento dos jovens na desocupação. As probabilidades dos homens inativos que migraram para somente estudar ou estudar e trabalhar mantiveram-se constantes em todo o período.

Dentre os homens nem-nem desocupados, o foco principal é a entrada no mercado de trabalho. $41 \%$ tornaram-se ocupados entre 2012 e 2014 . A partir de 2015 , devido às dificuldades de inserção no mercado de trabalho, as probabilidades se reduziram chegando em 2016 a 32\%. Dentre os demais, em torno de 15\% migraram para a inatividade, 5\% para somente estudar e $2 \%$ para estudar e trabalhar. Uma ressalva importante é que a probabilidade de um homem inativo migrar para a situação de somente estudar (10\%) foi o dobro da observada entre os homens desocupados (5\%). Ou seja, a opção pelo mercado de trabalho parece afastar de forma quase definitiva os homens jovens do sistema de ensino.

A situação de inatividade das mulheres difere bastante da verificada entre os homens.

Econômica-Niterói, v. 21, n. 1, p. 6-43. Junho, 2019 
Tabela 3 - Matrizes de probabilidades de transição dos homens segundo situação de atividade e frequência escolar $(\%)$ - médias anuais dos trimestres - Brasil - 2012-2016

\begin{tabular}{|c|c|c|c|c|c|}
\hline \multicolumn{6}{|c|}{ Homens 2012} \\
\hline \multirow{2}{*}{ Situação inicial } & \multicolumn{5}{|c|}{ Situação final } \\
\hline & Estuda e Trabalha & Somente Estuda & Somente Trabalha & Nem-nem inativo & Nem-nem desocupado \\
\hline Estuda e Trabalha & 65,5 & 14,0 & 17,8 & 1,5 & 1,2 \\
\hline Somente Estuda & 11,7 & 78,3 & 3,2 & 4,7 & 2,0 \\
\hline Somente Trabalha & 3,8 & 0,9 & 87,2 & 3,9 & 4,2 \\
\hline Nem-nem inativo & 2,3 & 8,7 & 26,3 & 50,5 & 12,3 \\
\hline Nem-nem desocupado & 2,4 & 4,5 & 42,2 & 15,5 & 35,4 \\
\hline \multicolumn{6}{|c|}{ Homens 2013} \\
\hline \multirow{2}{*}{ Situação inicial } & \multicolumn{5}{|c|}{ Situação final } \\
\hline & Estuda e Trabalha & Somente Estuda & Somente Trabalha & Nem-nem inativo & Nem-nem desocupado \\
\hline Estuda e Trabalha & 62,8 & 14,7 & 19,2 & 1,9 & 1,4 \\
\hline Somente Estuda & 11,4 & 77,8 & 3,6 & 5,2 & 2,0 \\
\hline Somente Trabalha & 4,2 & 1,1 & 86,8 & 4,0 & 3,9 \\
\hline Nem-nem inativo & 2,5 & 10,7 & 25,9 & 48,6 & 12,4 \\
\hline Nem-nem desocupado & 3,1 & 5,7 & 41,3 & 16,5 & 33,4 \\
\hline \multicolumn{6}{|c|}{ Homens 2014} \\
\hline \multirow{2}{*}{ Situação inicial } & \multicolumn{5}{|c|}{ Situação final } \\
\hline & Estuda e Trabalha & Somente Estuda & Somente Trabalha & Nem-nem inativo & Nem-nem desocupado \\
\hline Estuda e Trabalha & 64,2 & 14,4 & 18,5 & 1,7 & 1,3 \\
\hline Somente Estuda & 10,3 & 79,4 & 3,2 & 4,9 & 2,2 \\
\hline Somente Trabalha & 3,8 & 1,0 & 87,3 & 3,9 & 4,0 \\
\hline Nem-nem inativo & 2,1 & 10,0 & 24,3 & 49,9 & 13,6 \\
\hline Nem-nem desocupado & 2,4 & 5,7 & 40,5 & 15,4 & 35,9 \\
\hline \multicolumn{6}{|c|}{ Homens 2015} \\
\hline \multirow{2}{*}{ Situação inicial } & \multicolumn{5}{|c|}{ Situação final } \\
\hline & Estuda e Trabalha & Somente Estuda & Somente Trabalha & Nem-nem inativo & Nem-nem desocupado \\
\hline Estuda e Trabalha & 64,0 & 16,3 & 16,5 & 1,6 & 1,7 \\
\hline Somente Estuda & 9,9 & 80,0 & 2,7 & 4,7 & 2,7 \\
\hline Somente Trabalha & 3,8 & 0,9 & 86,2 & 4,1 & 5,1 \\
\hline Nem-nem inativo & 1,8 & 9,9 & 22,7 & 49,7 & 15,9 \\
\hline Nem-nem desocupado & 1,9 & 5,3 & 36,8 & 15,0 & 41,1 \\
\hline \multicolumn{6}{|c|}{ Homens 2016} \\
\hline \multirow{2}{*}{ Situação inicial } & \multicolumn{5}{|c|}{ Situação final } \\
\hline & Estuda e Trabalha & Somente Estuda & Somente Trabalha & Nem-nem inativo & Nem-nem desocupado \\
\hline Estuda e Trabalha & 64,5 & 16,2 & 16,0 & 1,5 & 1,7 \\
\hline Somente Estuda & 8,6 & 81,8 & 2,3 & 4,4 & 3,0 \\
\hline Somente Trabalha & 3,3 & 0,9 & 85,3 & 4,2 & 6,3 \\
\hline Nem-nem inativo & 1,7 & 9,8 & 20,8 & 48,9 & 18,8 \\
\hline Nem-nem desocupado & 1,6 & 4,8 & 32,2 & 15,4 & 46,0 \\
\hline
\end{tabular}

Fonte: Elaboração própria a partir da PNADC. 
32 Transições entre situações de atividade, inatividade e estudo dos jovens nem-nem no

Brasil - 2012/2016

Tabela 4 - Matrizes de probabilidades de transição das mulheres segundo situação de atividade e frequência escolar (\%) - médias anuais dos trimestres - Brasil - 2012-2016.

\begin{tabular}{|c|c|c|c|c|c|}
\hline \multicolumn{6}{|c|}{ Mulheres 2012} \\
\hline \multirow{2}{*}{ Situação inicial } & \multicolumn{5}{|c|}{ Situação final } \\
\hline & Estuda e Trabalha & Somente Estuda & Somente Trabalha & Nem-nem inativo & Nem-nem desocupado \\
\hline Estuda e Trabalha & 65,0 & 15,0 & 16,3 & 2,3 & 1,5 \\
\hline Somente Estuda & 8,7 & 79,9 & 2,2 & 6,8 & 2,4 \\
\hline Somente Trabalha & 4,3 & 1,1 & 82,1 & 8,5 & 4,1 \\
\hline Nem-nem inativo & 0,8 & 5,3 & 13,1 & 72,6 & 8,2 \\
\hline Nem-nem desocupado & 1,8 & 5,5 & 27,4 & 26,1 & 39,2 \\
\hline \multicolumn{6}{|c|}{ Mulheres 2013} \\
\hline \multirow{2}{*}{ Situação inicial } & \multicolumn{5}{|c|}{ Situação final } \\
\hline & Estuda e Trabalha & Somente Estuda & Somente Trabalha & Nem-nem inativo & Nem-nem desocupado \\
\hline Estuda e Trabalha & 63,4 & 16,4 & 16,3 & 2,5 & 1,4 \\
\hline Somente Estuda & 8,6 & 79,6 & 2,5 & 7,3 & 1,9 \\
\hline Somente Trabalha & 4,7 & 1,4 & 81,3 & 8,6 & 4,0 \\
\hline Nem-nem inativo & 1,2 & 6,3 & 13,6 & 70,9 & 8,0 \\
\hline Nem-nem desocupado & 2,1 & 5,8 & 27,4 & 29,1 & 35,7 \\
\hline \multicolumn{6}{|c|}{ Mulheres 2014} \\
\hline \multirow{2}{*}{ Situação inicial } & \multicolumn{5}{|c|}{ Situação final } \\
\hline & Estuda e Trabalha & Somente Estuda & Somente Trabalha & Nem-nem inativo & Nem-nem desocupado \\
\hline Estuda e Trabalha & 64,9 & 15,1 & 16,2 & 2,4 & 1,4 \\
\hline Somente Estuda & 7,7 & 80,8 & 2,2 & 7,0 & 2,3 \\
\hline Somente Trabalha & 4,4 & 1,2 & 82,3 & 8,5 & 3,6 \\
\hline Nem-nem inativo & 1,0 & 6,1 & 13,2 & 71,1 & 8,6 \\
\hline Nem-nem desocupado & 2,1 & 5,3 & 26,1 & 28,3 & 38,1 \\
\hline \multicolumn{6}{|c|}{ Mulheres 2015} \\
\hline \multirow{2}{*}{ Situação inicial } & \multicolumn{5}{|c|}{ Situação final } \\
\hline & Estuda e Trabalha & Somente Estuda & Somente Trabalha & Nem-nem inativo & Nem-nem desocupado \\
\hline Estuda e Trabalha & 66,2 & 15,5 & 14,6 & 2,0 & 1,7 \\
\hline Somente Estuda & 7,1 & 82,1 & 1,8 & 6,5 & 2,5 \\
\hline Somente Trabalha & 4,4 & 1,1 & 81,4 & 8,3 & 4,9 \\
\hline Nem-nem inativo & 0,7 & 6,1 & 12,4 & 70,0 & 10,8 \\
\hline Nem-nem desocupado & 1,4 & 5,6 & 23,1 & 26,7 & 43,1 \\
\hline \multicolumn{6}{|c|}{ Mulheres 2016} \\
\hline \multirow{2}{*}{ Situação inicial } & \multicolumn{5}{|c|}{ Situação final } \\
\hline & Estuda e Trabalha & Somente Estuda & Somente Trabalha & Nem-nem inativo & Nem-nem desocupado \\
\hline Estuda e Trabalha & 64,7 & 16,3 & 14,8 & 2,3 & 1,9 \\
\hline Somente Estuda & 6,8 & 83,1 & 1,6 & 5,5 & 3,0 \\
\hline Somente Trabalha & 4,3 & 1,0 & 80,7 & 8,2 & 5,8 \\
\hline Nem-nem inativo & 0,8 & 5,3 & 11,3 & 70,0 & 12,6 \\
\hline Nem-nem desocupado & 1,4 & 5,4 & 21,1 & 24,6 & 47,4 \\
\hline
\end{tabular}

Fonte: Elaboração própria a partir da PNADC.

Econômica-Niterói, v. 21, n. 1, p. 6-43. Junho, 2019 
Conforme já informado, cerca de $70 \%$ permaneceram inativas. Entre as $30 \%$ restantes que transitaram para outras situações $13 \%$ somente trabalharam e $8 \%$ ficaram desocupadas entre 2012 e 2014. Apenas 6\% migraram para somente estudar e 1\% para estudar e trabalhar. Em 2015 e 2016, a situação no mercado de trabalho também se tornou mais difícil para elas, reduzindo a probabilidade de conseguir trabalho e aumentando a desocupação.

Entre as mulheres desocupadas, a situação também se mostra mais difícil do que a dos homens. Embora as probabilidades de permanência na desocupação sejam um pouco mais elevadas entre as mulheres em relação aos homens, a transição para outras situações de atividade e frequência escolar mostraram-se diferentes. Em ambos os casos, existe uma relevante transição para a situação de somente trabalhar. Contudo, enquanto entre os homens cerca de $40 \%$ obtinham sucesso na sua colocação no mercado de trabalho, entre as mulheres desocupadas as probabilidades indicam que somente $27 \%$ conseguiram emprego e voltaram a trabalhar no período 2012/2014. Cerca de um quarto das mulheres desocupadas passa à inatividade, enquanto entre os homens a transição é bem menos frequente, $15 \%$. Com o recrudescimento da crise econômica, o acesso ao mercado de trabalho se reduziu, chegando em 2016 com apenas $21 \%$ das mulheres desocupadas migrando para o trabalho. As demais migraram principalmente para a inatividade, $25 \%$. Somente $5 \%$ das inativas voltaram a estudar, enquanto menos de $2 \%$ passaram a estudar e trabalhar.

O Gráfico 6 apresenta as probabilidades de transição dos homens e das mulheres entre as duas situações nem-nem. A mulher transita duas vezes mais da desocupação para a inatividade do que o homem. Enquanto o homem tem $50 \%$ mais chances de sair da inatividade para a desocupação do que a mulher. As transições da desocupação para a inatividade diminuíram no período pós-crise, enquanto as da inatividade para a desocupação cresceram em ambos os sexos.

O nível de escolaridade apresenta uma importante influência tanto para a permanência como para a transição dos jovens nem-nem entre a inatividade e a desocupação. Quanto menor o nível de escolaridade, maior a probabilidade de um jovem permanecer na inatividade e menor de permanecer desocupado. À medida em que o nível de escolaridade aumenta, as probabilidades vão se invertendo.

Mais de $70 \%$ dos jovens nem-nem com ensino fundamental incompleto permaneceram inativos de um trimestre ao outro entre 2012 e 2016 (Gráfico 7). Isso ocorre pois os menos escolarizados possuem maior dificuldade de acesso ao mercado de trabalho, principalmente as mulheres, que se torna ainda mais difícil quando associada à falta de experiência profissional. A desigualdade de gênero no trabalho não remunerado, ou seja, nos afazeres domésticos e cuidados de parentes, foi utilizada como justificativa para a inatividade por $30 \%$ das jovens que estão na condição nem-nem inativa (IBGE, SIS, 2017).

Menos de 30\% dos jovens nem-nem com ensino fundamental incompleto permaneceram como desocupados no período até 2014, aumentando no período de crise, em 2016, 
34 Transições entre situações de atividade, inatividade e estudo dos jovens nem-nem no Brasil - 2012/2016

Gráfico 6: Probabilidades de transiçāo entre desocupaçāo e inatividade segundo sexo - médias anuais dos trimestres - Brasil - 2012-2016

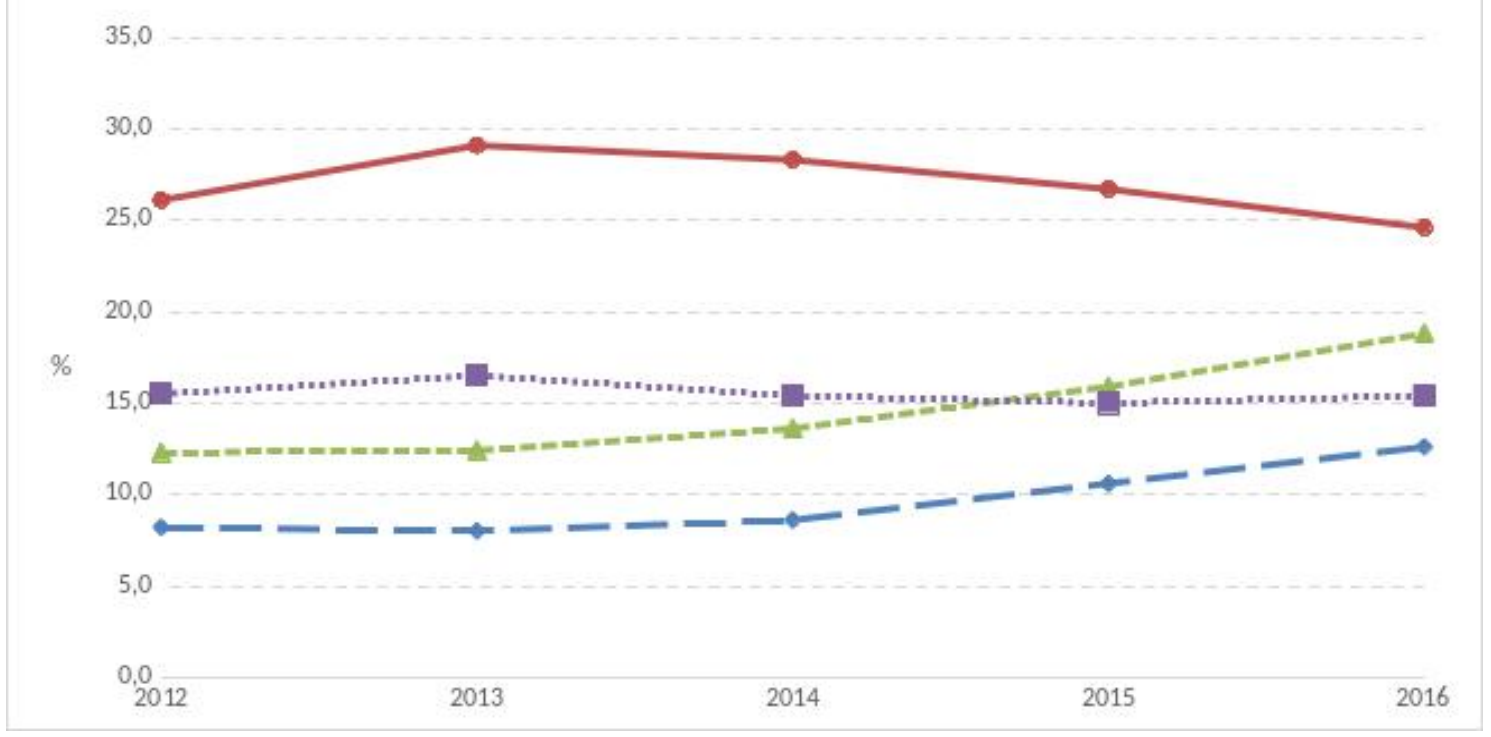

Fonte: Elaboração própria a partir da PNADC.

para $38 \%$, mas representando ainda a menor probabilidade de permanência dentre todos os níveis de escolaridade. Isso deve ocorrer ou porque esses jovens retornam para a inatividade ou, eventualmente, por aceitarem as piores ocupações no mercado de trabalho.

No outro extremo estão os jovens nem-nem com ensino superior completo, que possuíam taxas de permanência em torno de $50 \%$ tanto na inatividade como na desocupação. Tais jovens migraram mais fortemente para PEA do que os jovens com menor escolaridade, sendo, em média, $21 \%$ para a ocupação e $22 \%$ para a desocupação (Gráficos 8 e 9). Os jovens menos escolarizados migraram com probabilidades de $14 \%$ para a ocupação e $7 \%$ para a desocupação, em média.

Portanto, enquanto os jovens menos escolarizados possuem maiores probabilidades de permanecerem na inatividade, os jovens no mais alto grau de escolaridade possuem mais chances de migrar para a PEA, seja como ocupado seja como desocupado. Quanto maior o nível de escolaridade mais facilidade o jovem encontra para sair da condição inativa.

Aqueles que estavam desocupados apresentaram probabilidades pouco diferenciadas para se inserirem em uma ocupação no mercado de trabalho segundo o nível de escolaridade. Os que possuem menores níveis de escolaridade apresentaram probabilidades ligeiramente superiores aos demais entre 2012 e 2014, provavelmente devido ao fato de aceitarem mais facilmente as ofertas de emprego existentes em momento de crescimento econômico. Contudo, a partir de 2015, esse grupo foi o mais afetado, com maior redução da transição para o mercado de trabalho, chegando em 2016 com a menor probabilidade,

Econômica-Niterói, v. 21, n. 1, p. 6-43. Junho, 2019 


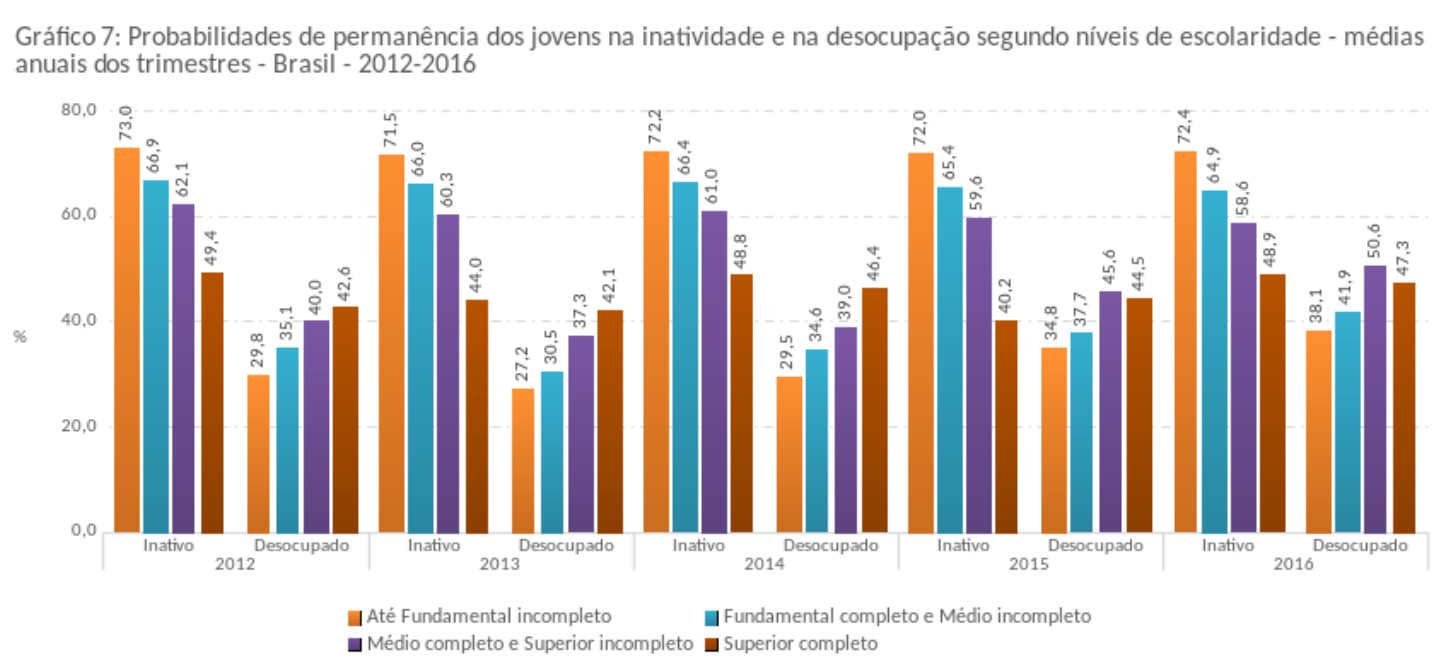

Fonte: Elaboração própria a partir da PNADC.

Gráfico 8: Percentual de jovens nem-nem inativos e desocupados que inverteram suas condiçōes segundo níveis de escolaridade - média dos trimestres - Brasil - 2012-2016

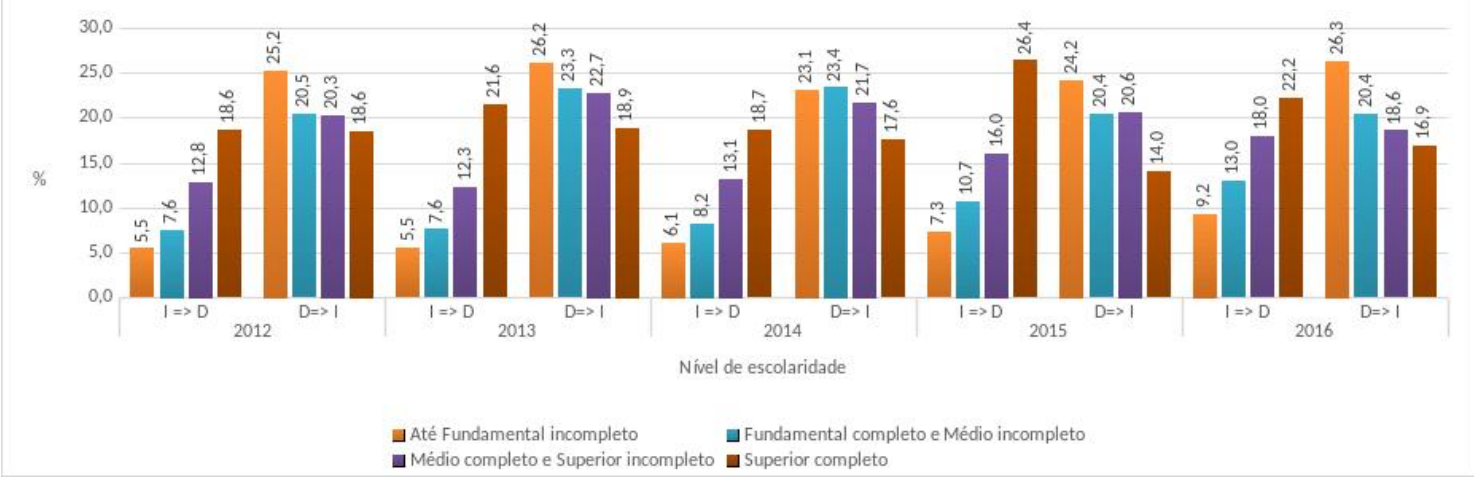

Fonte: Elaboração própria a partir da PNADC. 


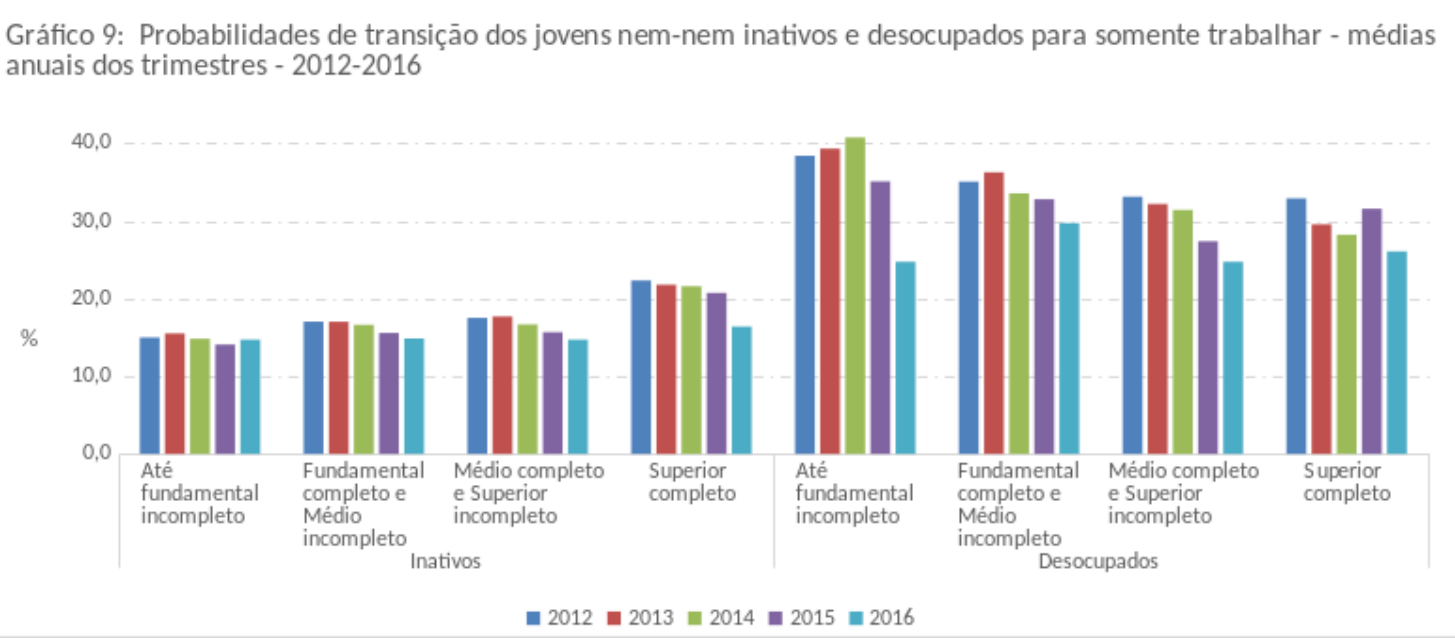

Fonte: Elaboração própria a partir da PNADC.

25\%. Os demais jovens também sentiram dificuldades de conseguir uma ocupação, contudo a redução na transição foi menor.

Outro ponto a salientar é que quando o nível de escolaridade cresce, aumenta o percentual de jovens inativos que migram para a situação de somente estudar. Entre os desocupados, a transição para o sistema de ensino ocorre principalmente para os jovens com ensino fundamental completo e ensino médio incompleto (Gráfico 10).

É interessante também observar o aumento ocorrido nesse tipo de transição para o estudo entre os jovens com ensino superior no período de crise, demonstrando um interesse pelo aumento da formação educacional nesses momentos, de forma semelhante ao observado em alguns países europeus. A dificuldade de acesso ao mercado de trabalho faz com que parte dos jovens transfira sua atividade para o sistema de ensino. Isso, entretanto, só é possível nos casos de jovens que possuam renda domiciliar suficiente para atender às suas necessidades sem procurar o mercado de trabalho.

Ressalta-se ainda que o homem inativo tem o dobro da probabilidade de sair da inatividade para somente estudar do que a mulher inativa, $10 \%$ e $5 \%$, respectivamente. Na desocupação, as probabilidades são semelhantes, em torno de 5\%

Em termos regionais, as transições seguem o padrão nacional em muitos aspectos. Contudo, podem-se fazer algumas considerações:

- a probabilidade de permanência dos jovens na inatividade é um pouco mais elevada na regiões Nordeste (67\%) e Norte (65\%) (Gráfico 11). Nas regiões Sudeste e Sul, estava em $67 \%$ em 2012, mas recuou até chegar a $62 \%$ e $61 \%$, respectivamente, em 2016 . Na Região Centro-Oeste, a probabilidade manteve-se constante em torno de $62 \%$.

- a permanência na desocupação é mais elevada na região Sudeste, seguida pela região 


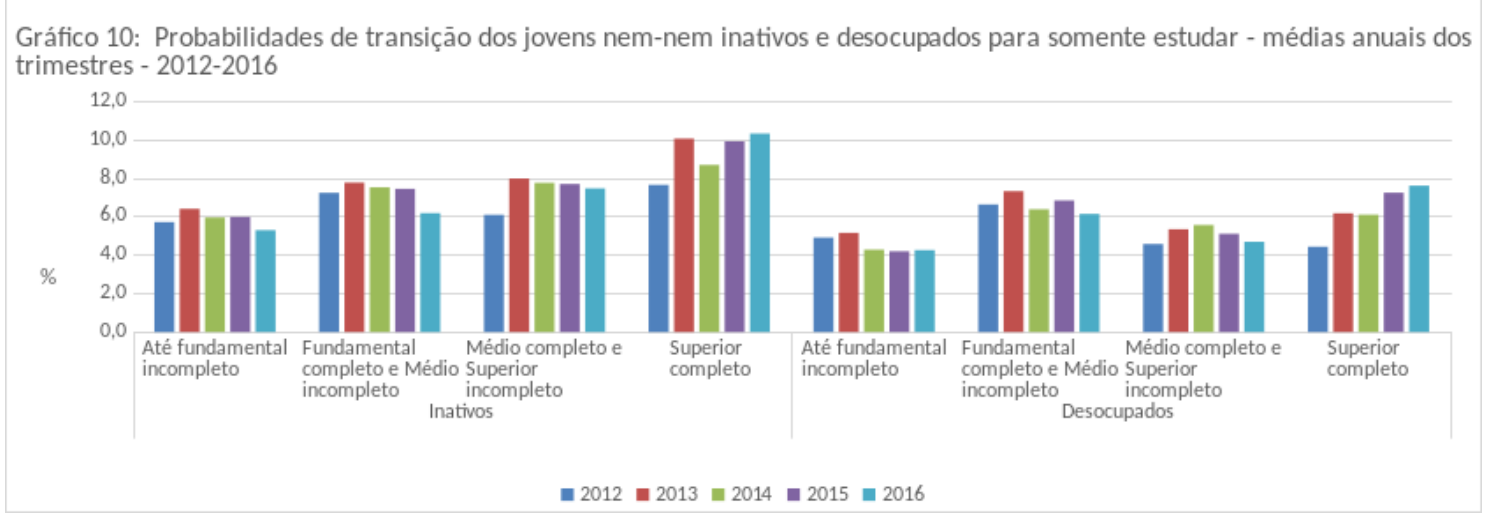

Fonte: Elaboração própria a partir da PNADC.

Nordeste, que possuem as maiores quantidades de jovens nem-nem no país (Gráfico 12). Essa probabilidade aumentou entre 2012 e 2016 de forma contínua em todas as regiões. Na Região Sudeste alcançou 52\% em 2016 ante a 40\% em 2012, enquanto na Região Nordeste foi de $43 \%$ ante a $37 \%$

Em resumo, as probabilidades nas matrizes de transição nos mostram que os jovens nem-nem que entram na situação de inatividade possuem maior probabilidade de permanecerem nela do que os que entram na de desocupação. Mais de $70 \%$ permanecem inativos entre dois trimestres, enquanto entre os desocupados essa probabilidade recua para cerca de $50 \%$.

A transição para as situações nem-nem é maior dentro das próprias situações nemnem. Ou seja, existe uma forte sinergia entre as condições de inatividade e de desocupação dos jovens nem-nem. Os jovens que mais migraram para a inatividade foram os que estavam desocupados e vice-versa. Para uma parcela dos jovens nem-nem, antes da inatividade houve a experiência frustrada de entrada no mercado de trabalho. A inatividade seria em parte um desalento para alguns jovens.

A permanência na inatividade é maior nas mulheres do que para os homens. Elas possuem mais dificuldades de migrarem para outras situações de atividade e de frequência escolar do que eles. Na transição para outras situações, prevalecem as relacionadas à entrada na população economicamente ativa (PEA), ou seja, passando para a situação de somente trabalhar ou para a desocupação.

Os homens possuem maior probabilidade de obter uma ocupação no mercado de trabalho do que as mulheres. Dos 50\% que transitam da inatividade para outras situações, $25 \%$ voltam a trabalhar e $12 \%$ ficam desocupados. Entre as $30 \%$ das mulheres inativas que transitam somente $13 \%$ voltam a trabalhar, $8 \%$ ficam desocupadas. No período de crise, a situação se deteriorou para ambos os sexos.

Os jovens menos escolarizados possuem maiores probabilidades de permanecerem na 
38 Transições entre situações de atividade, inatividade e estudo dos jovens nem-nem no Brasil - 2012/2016

Gráfico 11: Taxa de jovens nem-nem que permaneceram na inatividade segundo Grandes Regiões - médias anuais dos trimestres - 2012-2016

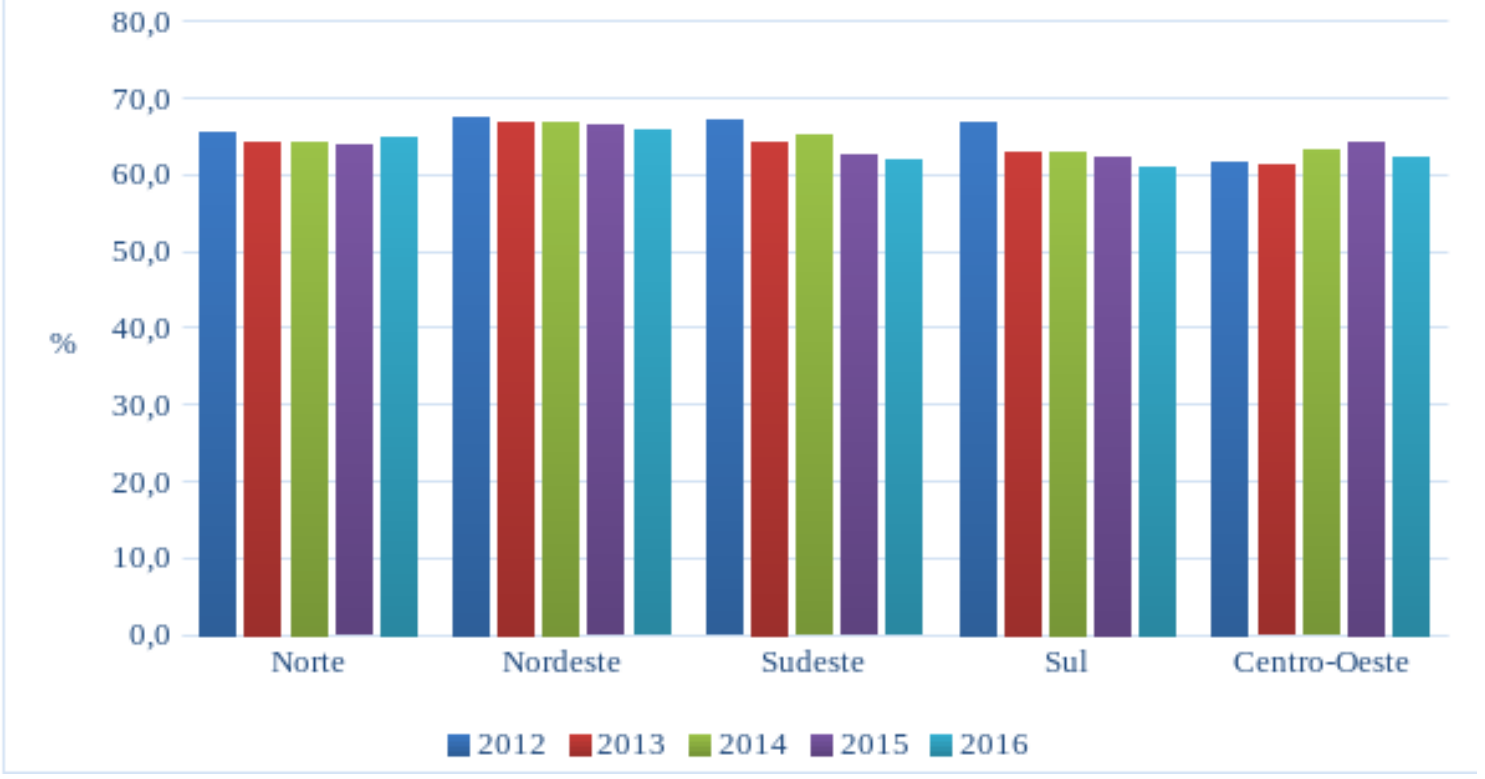

Fonte: Elaboração própria a partir da PNADC.

Econômica-Niterói, v. 21, n. 1, p. 6-43. Junho, 2019 


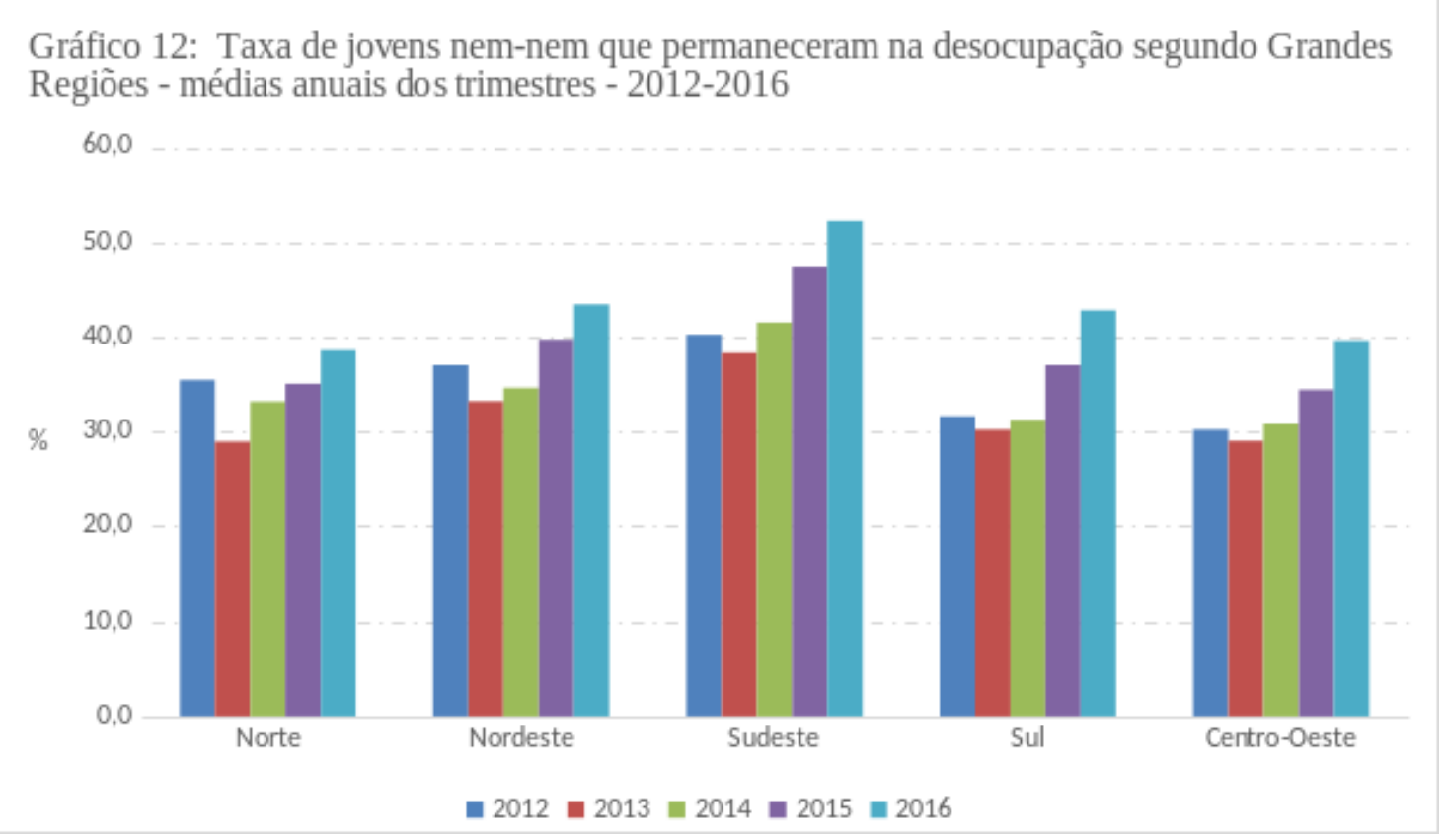

Fonte: Elaboração própria a partir da PNADC.

inatividade, enquanto os jovens no mais alto grau de escolaridade possuem mais chances de migrar para a PEA, seja na condição de ocupado ou desocupado. Quanto maior o nível de escolaridade mais facilidade o jovem encontra para sair da condição inativa.

A probabilidade do homem nem-nem inativo transitar para a situação de somente estudar é o dobro da chance da mulher inativa. Enquanto entre os desocupados, a probabilidade é semelhante. O que se retém é que o jovem nem-nem, seja inativo seja desocupado, quando transita desta para outras situações, em geral, o faz em direção ao mercado de trabalho. A escolha para a volta ao sistema de ensino é feita por uma minoria.

\section{Conclusão}

A principal contribuição do artigo é a análise desenvolvida sobre as probabilidades de transição dos nem-nem entre diferentes situações de atividade, inatividade e estudo, sendo explorados pela primeira vez os dados da PNADC de 2012 a 2016, cobrindo um período em que a economia desacelerou e terminou com a crise de 2015/2016. Por outro lado, é diferenciada a situação entre o nem-nem inativo e o desocupado. Conforme visto na resenha bibliográfica, trata-se de uma forma de desagregação pouco desenvolvida nos estudos acadêmicos sobre os nem-nem no Brasil.

Os resultados apresentados mostram que os subgrupos de jovens nem-nem inativos e 
40 Transições entre situações de atividade, inatividade e estudo dos jovens nem-nem no Brasil - 2012/2016

desocupados possuem determinantes e comportamentos de permanência e transição entre as situações de atividade e frequência escolar distintos. As diferenças são também significativas em relação ao sexo, ao nível de escolaridade e ao nível de rendimento domiciliar dos jovens.

Os jovens que estão em melhores condições sociais possuem mais facilidade de sair da condição de inatividade e de desocupação do que os demais. O baixo nível de renda domiciliar tem se mostrado como um dos principais entraves para a vida do jovem brasileiro. As desigualdades sociais, econômicas e regionais no país e a grande diferença na divisão sexual das tarefas domésticas e familiares estão no cerne da complexidade da condição nem-nem.

Uma das principais conclusões da análise das probabilidades de transição do artigo é que a população de jovens nem-nem possui um comportamento dinâmico no sentido de se renovar constantemente. Sem dúvida a renovação entre os inativos é mais lenta e certamente um conjunto deles, especialmente no caso das mulheres, permanece na condição de inatividade por longo prazo. Mas por outro lado, mesmo entre os inativos, a transição para o desemprego, para a situação de ocupado ou mesmo para o estudo não é desprezível, deixando claro que, embora o total de jovens nem-nem tenha se mantido relativamente estável no período analisado, há uma renovação constante da população nem-nem.

Ainda que essa população se renove, o fenômeno dos jovens nem-nem no Brasil é fortemente atrelado à figura feminina em decorrência das diferenças existentes na divisão sexual do trabalho que atribui à mulher a maior parte dos cuidados com parentes e das tarefas domésticas. A mulher permanece como a principal responsável pelo trabalho reprodutivo o que torna a sua trajetória no sistema de ensino e no mercado de trabalho mais difícil do que para os homens. A condição nem-nem representa o segundo maior grupo de situações de atividade, inatividade e frequência escolar entre as mulheres, atrás somente daquelas que somente trabalham. Entre os homens, representa o menor grupo.

Para que ocorra uma mudança estrutural nessa situação tornam-se prementes avanços na divisão sexual do trabalho reprodutivo com os homens compartilhando com as mulheres as atribuiçõos relativas aos cuidados com filhos, parentes e os afazeres domésticos. A mulher também tem o direito a decidir se prefere trabalhar e/ou estudar ou cuidar da família, mas isso deve ser uma escolha dela e não uma imposição pela permanência de uma estrutura social que ainda privilegia os homens. Essa situação está tão arraigada na sociedade brasileira que mesmo com a mudança de perfil dos jovens nem-nem, com redução das mulheres com filhos, o total de mulheres na condição nem-nem não recua.

Finalizando, seguem algumas sugestões de temas que poderiam ser explorados ampliando o conhecimento sobre a questão das transições dos jovens nem-nem. Seriam extensões naturais deste trabalho.

- Dar continuidade ao estudo das probabilidades de transição dos nem-nem ao final da atual crise econômica para verificar se a piora identificada em 2015/2016 teve continui-

Econômica-Niterói, v. 21, n. 1, p. 6-43. Junho, 2019 
dade ou se reverteu após a crise. Os dados trimestrais da PNADC se prestam a esse tipo de estudo.

- Analisar as probabilidades de permanência e de transição dos jovens nem-nem para as situações de atividade e frequência escolar em períodos superiores a um trimestre utilizando os próprios dados da PNADC com o intuito de avaliar como essas probabilidades se comportam em períodos mais longos.

- Explorar mais as transições dos jovens nem-nem segundo os três grupos etários $(15 / 17,18 / 24$ e 25/29 anos) para diferenciar a situação de cada um na medida em que se encontram em fases distintas em termos de formação educacional e de participação no mercado de trabalho.

\title{
Transitions between situations of activity, inactivity and study of Neet youth in Brazil - 2012/2016
}

\begin{abstract}
The young people who neither work nor study represent an expressive group in Brazil and have received more and more attention in the search for a better understanding. This article presents a bibliographical review of the studies already carried out on Brazilian NEET (not in education, employment, or training). It analyzes for the first time the probabilities of permanence and transition of these young people between the various situations of activity and school attendance. The study utilizes information from the National Survey by Continuous Household Sample in the period 2012/2016, when the economy went through a process of deceleration and crisis. The results point to a dynamism within the group of young NEET.
\end{abstract}

Keywords: NEET, youth employment, youth inactivity, youth schooling.

\section{Referências bibliográficas}

CABANAS, P.; KOMATSU, B. K.; FILHO, N. A. M. Crescimento da renda e as escolhas dos jovens entre os estudos e o mercado de trabalho. São Paulo, 2014.

CAMARANO, A. A.; KANSO, S. O que estão fazendo os jovens que não estudam, não trabalham e não procuram trabalho? Instituto de Pesquisa Econômica Aplicada (Ipea), 2012.

CAMARANO, A. A.; KANSO, S.; ANDRADE, A. Estão fazendo a transição os jovens que não estudam, não trabalham e não procuram trabalho. Transição para vida a adulta ou vida adulta em transição, 2006. 
42 Transições entre situações de atividade, inatividade e estudo dos jovens nem-nem no Brasil - 2012/2016

CAMARANO, A. A. et al. Caminhos para a vida adulta: as múltiplas trajetórias dos jovens brasileiro. Última década, Universidad de Chile. Facultad de Ciencias Sociales, v. 12, n. 21, p. 11-50, 2004.

CARDOSO, A. Juventude, trabalho e desenvolvimento: elementos para uma agenda de investigação. Caderno crh, Universidade Federal da Bahia, v. 26, n. 68, p. 293-314, 2013.

DENNETT, J.; MODESTINO, A. S.; CENTER, F. R. B. of B. N. E. P. P. Uncertain Futures? Youth Attachment to the Labor Market in the United State and New England. [S.l.]: Citeseer, 2013.

DEVILLE, J.-C.; SÄRNDAL, C.-E.; SAUTORY, O. Generalized raking procedures in survey sampling. Journal of the American statistical Association, Taylor \& Francis Group, v. 88, n. 423, p. 1013-1020, 1993.

EGAN, M.; DALY, M.; DELANEY, L. Childhood psychological distress and youth unemployment: Evidence from two british cohort studies. Social Science \& Medicine, Elsevier, v. 124, p. 11-17, 2015.

FILHO, N. A. M.; CABANAS, P. H. F.; KOMATSU, B. K. A condição "nem-nem” entre os jovens é permanente. Policy Paper, n. 7, 2013.

HASENBALG, C. A transição da escola ao mercado de trabalho. Origens e destinos: desigualdades sociais ao longo da vida. Rio de Janeiro: Topbooks, p. 147-172, 2003.

HOYOS, R. D.; FIERROS, C. G.; M, J. V. V. Idle youth in Mexico: trapped between the war on drugs and economic crisis. [S.1.]: The World Bank, 2016.

HOYOS, R. D.; POPOVA, A.; ROGERS, H. Out of school and out of work: a diagnostic of ninis in Latin America. [S.1.]: The World Bank, 2016.

IBGE. Pesquisa nacional por amostra de domicílios contínua, 2012-2016. documentação dos microdados, Rio de Janeiro:IBGE.

IBGE. Síntese de indicadores sociais : uma análise das condições de vida da população brasileira. IBGE, Coordenação de População e Indicadores Sociais. - Rio de Janeiro: IBGE, 2017.

JUNIOR, A. T.; SILVA, D.; VEIGA, A. Produção de pesos longitudinais para estimação e análise de dados da Pesquisa Mensal de Emprego do IBGE. Tese (Doutorado) Dissertação de Mestrado, Escola Nacional de Ciências Estatísticas, Rio de Janeiro, 2015.

LEME, M. C. da S.; WAJNMAN, S. A alocação do tempo dos adolescentes brasileiros entre o trabalho e a escola. Anais, p. 1-22, 2016.

Econômica-Niterói, v. 21, n. 1, p. 6-43. Junho, 2019 
MARTINS, J. S. Um estudo sobre os jovens que não estudam nem participam da força de trabalho no rio de janeiro (2004-2014). Monografia. Instituto de Economia. UFRJ., 2016.

MONTE, P. A. do; CIRÍACO, J. da S. A situação ocupacional e educacional dos jovens no brasil: 2002 a 2012. Revista de Economia, v. 38, n. 66, 2019.

MONTEIRO, J. Quem são os jovens nem-nem?: uma análise sobre os jovens que não estudam e não participam do mercado de trabalho. 2013.

MOTA, D. G. F. D. Os jovens que nem trabalham e nem estudam no brasil: Caracterização e transformações no período 2004/2015. Tese de Doutorado. IE/PPGE/UFRJ, 2018.

O'DEA, B. et al. A cross-sectional exploration of the clinical characteristics of disengaged (neet) young people in primary mental healthcare. BMJ open, British Medical Journal Publishing Group, v. 4, n. 12, p. e006378, 2014.

OSE, S. O.; JENSEN, C. Youth outside the labour force-perceived barriers by service providers and service users: A mixed method approach. Children and Youth Services Review, Elsevier, v. 81, p. 148-156, 2017.

PAIS, J. M. Ganchos, tachos e biscates: jovens, trabalho e futuro. Porto: Ambar, 2001.

RIBAS, R.; MACHADO, A. F.; GOLGHER, A. B. Flutuações e persistência na pobreza: uma análise de decomposição transitória-crônica para o brasil. Pesquisa e Planejamento Econômico, v. 41, n. 2, 2011.

ROJAS, H. A. G. et al. Modelos para estimar cambios brutos en encuestas rotativas con ausencia de respuesta en disenos de muestreo complejos. Tese (Doutorado) Universidad Nacional de Colombia.

SERRACANT, P. "Generació ni-ni": estigmatització i exclusió social: gènesi i evolució d'un concepte problemàtic i proposta d'un nou indicador. [S.1.]: Generalitat de Catalunya, Departament de Benestar Social i Família, 2012.

SIMÕES, A. Os Jovens que não estudam nem trabalham no Brasil e o Bolsa Família. [S.1.]: Brasília, 2013.

VASCONCELLOS, M.; SILVA, P.; SZWARCWALD, C. Aspectos de amostragem da pesquisa mundial de saúde no brasil. Cadernos de Saúde Pública, Rio de Janeiro, v. 41, n. 21, 2005.

Recebido em 14 de maio de 2018. Aceito para publicação em 05 de agosto de 2019. 